Portland State University

PDXScholar

Summer 1-1-2012

\title{
Assessing Environmental Inequality in Portland, Oregon: An Exploration of Local Environmental Justice Struggles
}

Jordan Douglas Folks

Portland State University

Follow this and additional works at: https://pdxscholar.library.pdx.edu/open_access_etds

Part of the Inequality and Stratification Commons, Place and Environment Commons, and the Race and Ethnicity Commons

Let us know how access to this document benefits you.

\section{Recommended Citation}

Folks, Jordan Douglas, "Assessing Environmental Inequality in Portland, Oregon: An Exploration of Local Environmental Justice Struggles" (2012). Dissertations and Theses. Paper 450.

https://doi.org/10.15760/etd.450

This Thesis is brought to you for free and open access. It has been accepted for inclusion in Dissertations and Theses by an authorized administrator of PDXScholar. Please contact us if we can make this document more accessible: pdxscholar@pdx.edu. 
Assessing Environmental Inequality in Portland, Oregon: An Exploration of Local

\title{
Environmental Justice Struggles
}

\author{
by \\ Jordan Douglas Folks
}

A thesis submitted in partial fulfillment of the requirements for the degree of

\author{
Master of Science \\ in \\ Sociology
}

Thesis Committee:

Veronica Dujon, Chair

Amy Lubitow

Hyeyoung Woo

Portland State University

(C)2012 


\begin{abstract}
This thesis explores patterns of environmental inequality in Portland, Oregon; both the existence of spatial environmental inequalities and the structural and local forces which contribute to them. Research on environmental inequality, or inequitable exposure to toxins, has shown that minority and low-income populations experience the bulk of the exposure to environmental hazards. Although Portland is often cited as the archetype of a sustainable city, environmental inequality is a pervasive issue. This thesis examines the health inequalities that characterize underserved communities in Portland.

Utilizing a mixed methods approach, the researcher uses 1) logistic regression to statistically assess the relationship between race, poverty, and Superfund site locations, and 2) in-depth interviews with members of Oregon's environmental justice movement to help understand the historical, social, political, and economic conditions of Portland and their subsequent influence on environmental inequalities. Quantitative data is pooled from 2000 census and 2011 Environmental Protection Agency (EPA) sources. The quantitative findings demonstrate that environmental inequality is present in Portland, with African Americans being particularly overrepresented in tracts with Superfund sites. The quantitative analyses ultimately suggest that minimally populated, highly impoverished tracts with approximately $11 \%$ African American residents are most likely to house a Superfund site. The qualitative findings show that a variety of structural and local forces play prominent roles in the formation of Portland's environmental inequalities. The qualitative analyses reveal this to be a multifaceted and complex process that is indicative of Portland's history of racial inequality, contemporary free market and
\end{abstract}


business forces, and governmental interests which culminate in trends of inequitable development. 


\section{Acknowledgements}

Thank you to all who helped, guided, and supported me along the way. I could not have completed this thesis without my cohort, friends, family, loved ones, and the Sociology faculty at Portland State University. A special thanks is due to my wonderful thesis committee: Veronica Dujon, Amy Lubitow, and Hyeyoung Woo. Your hard work and dedication to students like myself is the reason that I and so many others in PSU's Sociology Department have succeeded in the thesis world and beyond. 


\section{Table of Contents}

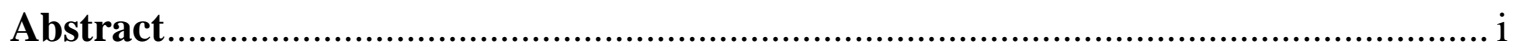

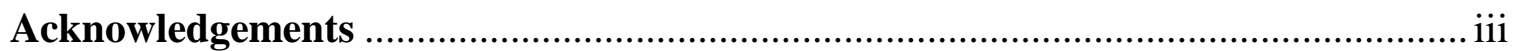

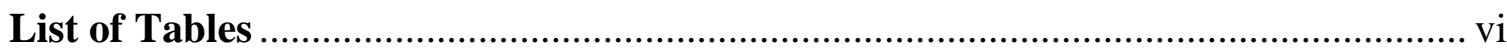

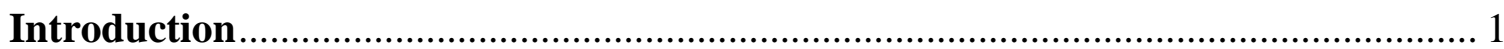

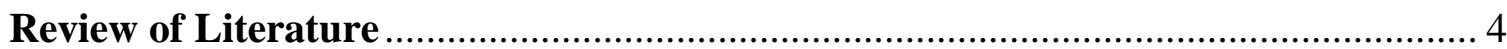

Environmental Sociology and the Built Environment ............................................. 4

Health Disparities, Segregation, and the Social Determinants of Health......................... 6

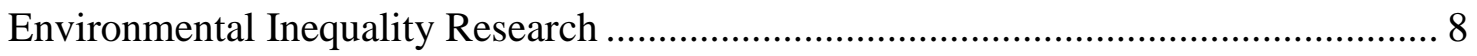

Environmental Inequality in Portland, Oregon ...................................................... 15

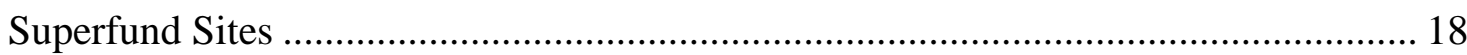

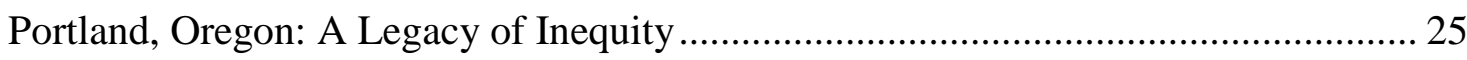

Environmental Inequality Formation ...................................................................... 30

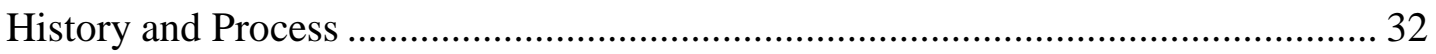

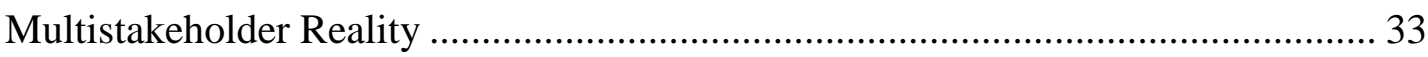

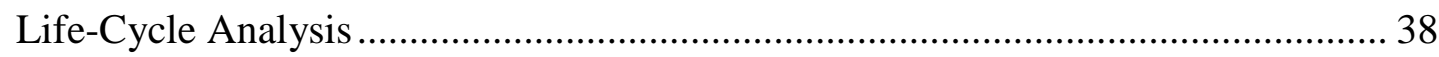

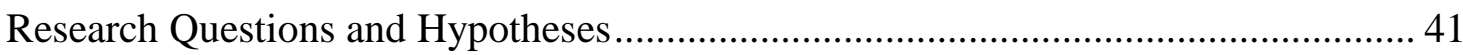

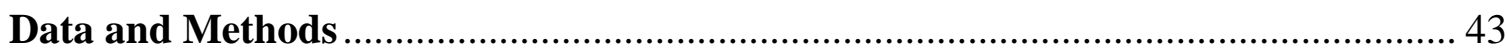

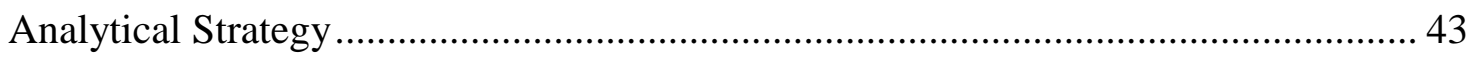

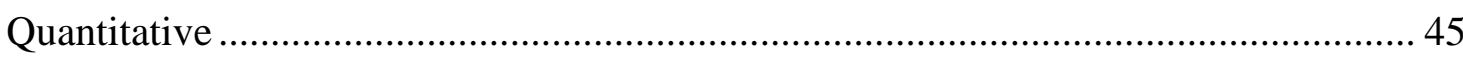

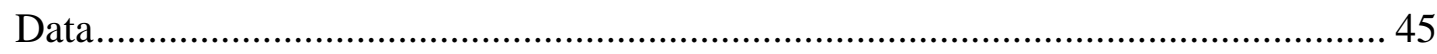

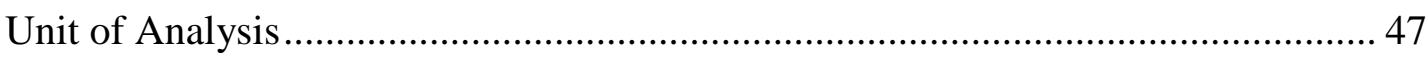

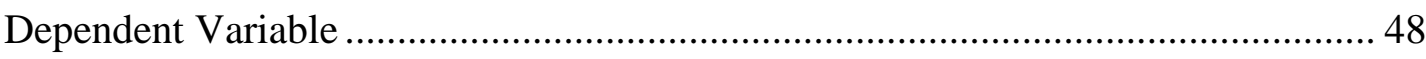

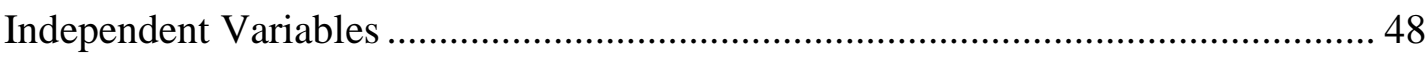

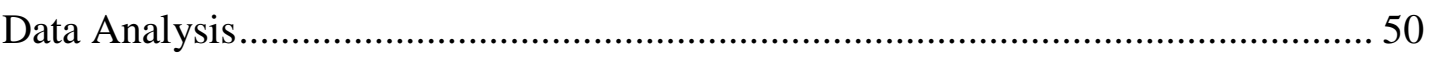

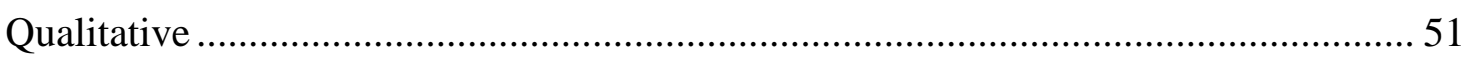

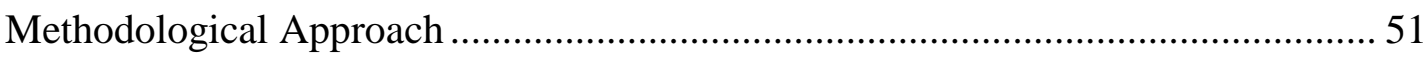

Sample

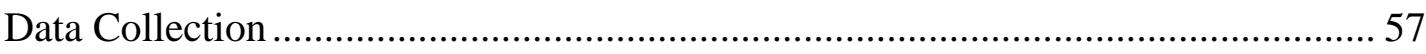

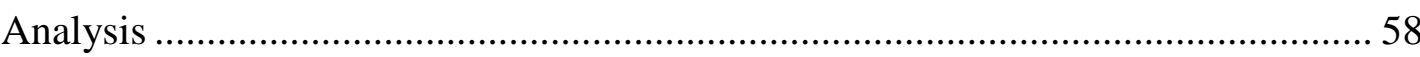

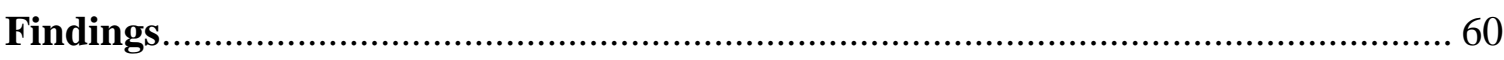

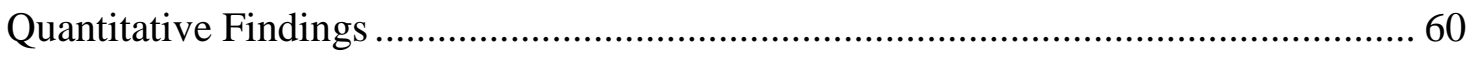

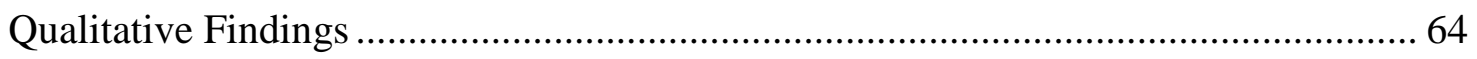




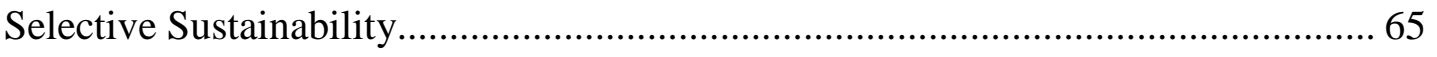

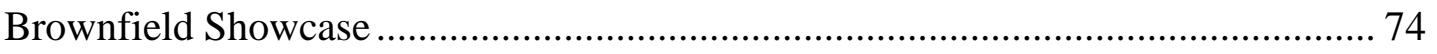

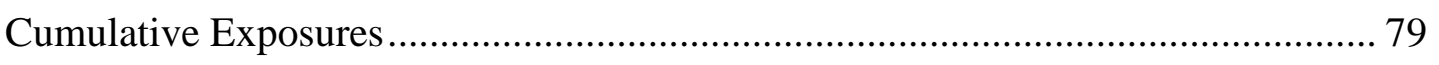

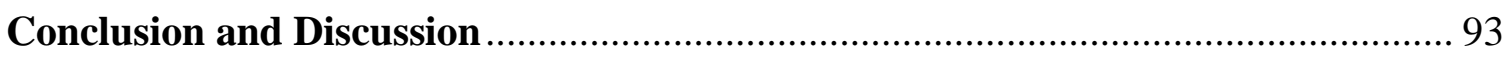

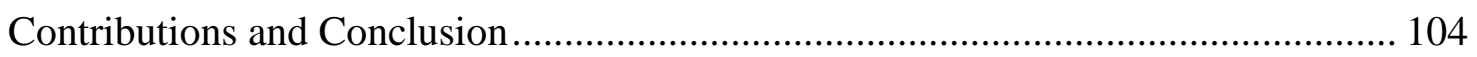

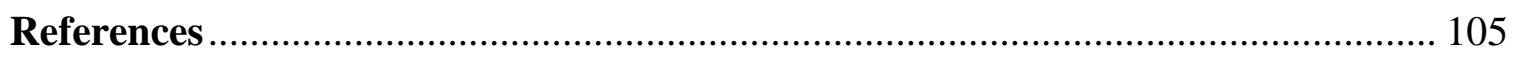

Appendix: Interview Guide ......................................................................... 115 


\section{List of Tables}

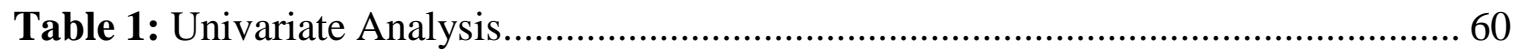

Table 2: Logistic Regression Models Predicting Superfund Site Presence .................... 62 


\section{Introduction}

Harlem residents were overjoyed upon hearing that the Fresh Kills landfill would be closed in 2001. However their elation would be short lived and the foul odor that permeated the surrounding area would soon return. By 2003, Mayor Bloomberg's administration reopened the site so it could be used as a marine transfer station; part of a new system that shifts the transportation of waste from roadways to waterways (Lee 2003). Locals were outraged, as this was just one of many toxic waste facilities that were concentrated in the African American community. Residents of the community argued that the administration was putting hazardous facilities in Harlem at considerably higher rates than other parts of the city. "We have two very large sewage treatment plants. We have six out of the eight diesel bus depots in Manhattan. And we've got three Department of Sanitation truck facilities" remarked one resident (Lee 2003). Community members did not see the prevalence of hazardous sites in their neighborhoods as a mere coincidence. Instead, they claimed the disproportionate siting was an intentional act and that Harlem was targeted due to its social characteristics, particularly its high rates of poverty and African American residents. In response, public officials defended that the site was re-chosen for financial feasibility reasons and assured the community that it was not being singled out (Lee 2003).

This historical account illustrates the phenomenon known as environmental inequality, where particular social groups are disproportionately burdened by environmental hazards (Bullard et al. 2007; Pellow 2002). Much research has shown that certain segments of the American population - particularly racial minorities and the poor 
- live and work in environments that are significantly more toxic than other parts of their home cities (Bullard et al. 2007; Bowen 2002). However, just like the debate between Harlem residents and city officials, there is much debate in the academic literature over whether or not marginalized communities are intentionally targeted as dumping grounds (Mohai and Bryant 1992). Do corporations and governments, motivated by racism and greed, purposefully choose poor and minority communities as sites for hazardous facilities? Perhaps free market forces create this unfortunate scenario? Or is it just a coincidence?

As these unanswered questions demonstrate, there is still much to learn about the processes behind environmental inequalities and the academic literature lacks much sociological explanation of its outcomes. This is largely in part to the overreliance on quantitative designs which not only neglect to consider the histories behind the environmental inequalities, but are also unable to uncover any of the structural or local forces which have contributed to the problem (Pellow 2000). Without a rigorous exploration of the unique histories behind these inequalities, it is difficult to understand how they came to be. The research presented in this thesis attempts to bridge this gap by quantitatively examining environmental inequality in Portland, Oregon and then qualitatively exploring the historical, structural, and local forces which have created and maintained these inequities in an attempt to help explain the outcomes presented in the quantitative results and to better our understanding of how environmental inequalities have formed in a major American city. 
Considering Portland is hailed as one of the "greenest" cities in America (Shandas and Messer 2008), this study serves to expose some of the shortcomings of one of the most eco-friendly places in the U.S. Even though Portland may rank extremely high in environmental quality, environmental health disparities have previously been found in the Portland area (Smith 2009; Urban League of Portland 2009; Downey 2006). Thus, any instances of environmental inequality found in the qualitative and quantitative data are considerably magnified when one considers Portland's green reputation. Specifically, instances of environmental inequality offer a stark contrast to the high levels of environmental quality that characterize many of Portland's neighborhoods. Therefore, this study partially serves to challenge the city's reputation for sustainability, particularly in regard to the social component of sustainability (Dillard, Dujon, and King 2009). 


\section{Review of Literature}

This chapter serves to not only explore previous environmental inequality research, but to put it in a sociological and historical context. It begins with an examination of core concepts - such as the built environment, social determinants of health, and segregation - which underlie environmental inequality research and theory. Then, an extensive review of the environmental inequality literature is provided; including previous findings, the methodological and race/class debates, and studies that focus on Portland. Subsequently, the history and current state of Superfund sites is reviewed. The chapter concludes with an examination of Portland's marked history of segregation and racial inequality.

\section{Environmental Sociology and the Built Environment}

Environmental inequality research has extensive and diverse academic roots. The following paragraphs provide an outline of its scholarly lineage. In the early 1970's, sociology witnessed a surge of research and writing on human-environmental interactions and systems; challenging traditional anthropocentric sociological paradigms which customarily omitted the natural environment (and its overarching influence) from social theory and research (Buttel and Humphrey 2002). William R. Burch Jr.'s Daydreams and Nightmares: A Sociological Essay on the American Environment (1971) and Samuel Z. Klausner's On Man in His Environment (1971) were revolutionary in this regard, as the two texts offered some of the first major sociological explorations on the interwoven connections between society, the environment, and human interactions. Over the course of the decade an increasing number of sociologists began to embrace this new theoretical 
framework and "environmental sociology" was coined as a moniker for the burgeoning subfield (Catton and Dunlap 1978).

As environmental sociologists began to analyze the immense influence of the environment on social phenomena, it became clear that the core concept of "environment" needed sociological exploration. Social scientists divided the environment into two parts: the built and the natural environment, each resting on opposite sides of a continuum. The natural environment is defined as the various organic entities which collectively make up the earth; forests, mountains, oceans, the creatures that dwell within them, the air they breathe, and so on. Conversely, the built environment consists of tangible human-made structures which are intended for repeated use (Dunlap, Michelson and Stalker 2002). As virtually all social interaction takes place within the context of a particular built environment, environmental sociologists are especially interested in how the built environment shapes and manifests sociological phenomena. As Dunlap, Michelson and Stalker (2002) explain:

Built environments are created by certain people for themselves or other people. How and why this creative process takes the path it does is a social process. Understanding how environments get built; what objects are chosen; how products and artifacts are distributed; and who benefits, who loses and in what way; are all matters of major importance that call for sociological analysis. (P. 4)

This conceptual orientation is of core significance to the research being undertaken here and must be considered when examining environmental inequality and the interrelated research presented in this literature review. 


\section{Health Disparities, Segregation, and the Social Determinants of Health}

The built environment is dramatically influential on the social, physical, and psychological wellbeing of individuals and communities at large. As a growing body of research suggests that health is largely influenced by one's physical and social environment (Marmot, Siegrist and Theorell 2006; Stafford and McCarthy 2006), it is not surprising that various health disparities are often linked back to the built environment. For example, research has demonstrated that dietary choices are influenced by the availability and type of food stores in a given area (Morland et al. 2002). Since diet has been consistently linked to health outcomes (Baker 2007; Centers for Disease Control 2003), food type and availability is increasingly problematic for low-income and minority neighborhoods as they often lack proper grocery stores and are alternatively dominated by unhealthy food options such as fast-food, liquor stores, and convenience stores (LaVeist and Wallace 2002; Morland et al. 2002; Curtis and McClellan 1995). These marginalized urban communities have been labeled "food deserts" by academic researchers and are increasingly common in segregated inner-city neighborhoods (Whelan et al. 2002; Wrigley et al. 2002).

The reasons as to why health inequalities are so persistent have plagued academics for decades. While it is undoubtedly a multifaceted and complex set of systemic causes, America's history of racial and economic segregation sets the stage for a variety of health disparities which stem from the built environment. Racial segregation has been a prominent feature of U.S. society virtually since its inception, with non-whites traditionally occupying the most disadvantaged places within the socioeconomic 
spectrum (Massey and Denton 1993). Specifically, Massey and Denton's research links the persistent poverty experienced by racial minorities in the U.S. to the segregated nature of American cities. However, the nature and extent of this separation has evolved over the years; racial segregation has shifted from a macro level phenomenon (counties and states) to the micro level of neighborhoods (Massey and Hajnal 1995). In addition, the blatant housing, lending and legal discrimination against non-whites which propelled racial segregation was slowly ameliorated through the civil rights legislation of the 1960s and 1970s (Katznelson 2005). Due the legal and social progress from the civil rights era, levels of racial segregation have slowly waned; however they still constitute a significant feature of stratification in the U.S. (Massey and Denton 1993).

While class segregation is not as dramatic as racial segregation (Massey, Domina, and Rothwell, 2009), significant economic segregation nevertheless characterizes U.S. society (Rothwell and Massey 2010; Watson 2006). Moreover, racial and economic segregation are intricately intertwined in U.S. society. Lack of adequate educational and economic opportunities and the intense concentration of poverty are hallmarks of racially segregated communities (Williams and Collins 2001). As the previous food desert example illustrates, poor health outcomes and health disparities have been consistently linked with racial and economic segregation. Williams and Collins (2001) explain that the poor educational and economic opportunities in racially segregated communities are the primary mechanisms that facilitate significant health disparities. This scenario is further compounded by the lack of safe and adequate housing (Kramer and Hogue 2009; Williams and Collins 2001) and healthy food options (LaVeist and Wallace 2002; 
Morland et al. 2002; Curtis and McClellan 1995). As a result, low birth weights (Grady 2007), premature mortality (Cooper et al. 2001), elevated cancer and heart disease mortality rates (Collins 1999) and more have been shown to be tangible health outcomes of segregation.

As Wilkinson and Marmot (2003) explain, the connection between social structures and health outcomes is conceptualized as the "social determinants of health." In sum: “[p]eople's lifestyles and the conditions in which they live and work strongly influence their health" (p. 8). As the preceding paragraphs demonstrate, the built environment is a critical component of the social determinants of health. These concepts are invaluable as they help define key theoretical assumptions that underlie environmental inequality research.

\section{Environmental Inequality Research}

Broadly, environmental inequality (or alternatively, environmental justice) research seeks to examine the inequitable distribution of detrimental environmental health and social outcomes which stem from the built environment (Downey and Hawkins 2008). While researchers began to find associations between air pollution and socioeconomic status as early as the 1970's (Asch and Seneca 1978), racial discrepancies in environmental quality were not assessed until the following decade (Bullard 1983; U.S. General Accounting Office 1983). The United Church of Christ Commission for Racial Justice (1987) is regarded as a landmark study on environmental inequality. The national study compared the relationship between income, race, and propinquity to hazardous waste facilities; concluding that nonwhites and low-income residents were 
disproportionately represented near waste facilities and that race was the strongest predictor of proximity to a waste site. These findings were confirmed by later studies which continued to find strong associations between minority status and proximity to waste facilities (Bullard et al. 2007; Downey 2003; Ringquist 1997; Mohai and Bryant 1992).

As Downey et al. (2008) explain, the bulk of quantitative environmental inequality studies have focused solely on black/white disparities. However, Latino communities are commonly disproportionately burdened by toxins as well (Crowder and Downey 2010; Downey 2006; Pastor, Sadd and Morello-Frosch 2002; Hird and Reese 1998). Downey's (2006) analyses of 14 metropolitan areas spanning the U.S. concluded that "Hispanic disparate social impacts and relative distribution inequality are more widespread than" that of blacks" (p. 36). Despite the relatively shallow literature base on the two racial groups, Native American (Shriver and Webb 2009; Brown, Ciambrone and Hunter 1997) and Asian populations (Elkind 2006; Brown et al. 1997) have also been adversely affected by inequitable toxic exposure.

In addition to the racial discrepancies of toxin exposure, many environmental inequality studies have found a relationship between environmental hazards and socioeconomic status. ${ }^{1}$ Impoverished neighborhoods are more likely to be plagued by industrial pollution than their socioeconomically affluent counterparts (Smith 2009; Derezinski, Lacy and Stretesky 2003; Chakraborty and Armstrong 1997; Hamilton 1995; Mohai and Bryant 1992; Asch and Seneca 1978). In fact, findings on the effect of income

\footnotetext{
${ }^{1}$ Several studies have found no, inconsistent, or weak evidence of environmental inequality in their analyses. See Derezinski et al. 2003, Atlas 2002, and Bowen et al. 1995.
} 
on toxin proximity and exposure have been more consistent than that of race (Bowen 2002). Similarly, neighborhood education levels have also been shown to have a negative relationship with pollution exposure (Crowder and Downey 2010). Similar to the race/class connection that characterizes segregation in the U.S., race and socioeconomic status are also intricately intertwined in the context of environmental inequality. Many studies find both race and income to be significant predictors of hazard exposure (Smith 2009; Bullard et al. 2008; Derezinski et al. 2003; Chakraborty and Armstrong 1997; United Church of Christ 1987), with Smith (2009) concluding that economically deprived African Americans are at highest risk. However, the strength of income inequality as a predictor of toxin presence varies from race to race (Downey et al. 2008).

Due to the competing explanations of race versus socioeconomic status as the ultimate predictor of disproportionate hazard exposure, the literature is characterized by a debate over the salience of minority or poverty status in predicting environmental inequalities (Crowder and Downey 2010). However this debate is a relatively arbitrary one, especially considering the vast differences in methodologies used across the spectrum of environmental inequality research (Bowen 2002; Holifield 2001; Mohai 1995). Since researchers utilize a myriad of different comparison populations, hazard indicators, statistical models, and units of analysis, it is not surprising that environmental inequality results are extremely varied (Holifield 2001). Furthermore, inconsistencies between findings are perpetuated by varied definitions of "environmental inequality" from study to study (Downey 2006). 
Baden, Noonan and Turaga's (2007) study demonstrates how slight variations in quantitative designs exhibit dramatically different findings. The authors find radical discrepancies between logistic regression results when different units of analysis are employed for the same area. The same logit models are used for three geographic areas (entire U.S., California, and LA County) across four units of analysis (county, Zip code, tract, and block group). The resulting conclusions are extremely inconsistent. For example, at the national level percent Hispanic is significant ( $\mathrm{p}<.05)$ and negatively associated with [National Priority List] Superfund sites when counties are used as the unit of analysis, but this relationship becomes positive ( $\mathrm{p}<.001)$ when Zip codes, tracts, and blocks (respectively) are employed. And while percent black is only significant $(\mathrm{p}<.001)$ for California's tracts and block groups, it fails to exhibit significant coefficients for any of the four units of analysis for LA County. As this study shows, variations in modeling assumptions and designs can contribute to incongruent findings. Rather than contradict each other, discrepancies in results demonstrate that environmental inequality varies in form, severity, time, and place. As Downey (2006) concludes, all the various methods and results are pieces of a larger puzzle which collectively serve to illustrate environmental inequality phenomena around the U.S. ${ }^{2}$

Despite the varied methods of environmental justice studies, one methodological trend continues to dominate the literature: quantitative analysis. Bowen's (2002) extensive environmental justice literature review demonstrates the quantitative leanings of the sub-field; all of the studies analyzed in the article employ statistical modeling. In

\footnotetext{
${ }^{2}$ Much of the American environmental inequality literature is U.S. centric and this paper will similarly focus on the issue within the context of a U.S. city. See Pellow 2007 and Byrne, Glover, and Martinez 2002 for an international perspective and several international environmental inequality case studies.
} 
the face of the virtual omnipresence of quantitative methods within the literature, a few studies took the qualitative path of research instead (Pellow 2007; Pellow 2004; Pellow 2000; Boone and Modarres 1999; Hurley 1997; Pulido et al. 1996; Čapek 1993). These authors rely on case studies (participant observation, interviews, and content analysis) and ethnographies to assess environmental inequality in a given area, often with the specific aim of accounting for the historical processes that have led to the current state of environmental inequity. Researchers use case studies to demonstrate how real estate dynamics (Hurley 1997), land-use zoning (Boone and Modarres 1999), racialized divisions of labor, planning practices, and other processes (Pulido et al. 1996) crafted the current environmental inequities in the cities studied. Pulido et al. (1996) contend that qualitative methods must be used when attempting to expose the complex historical and geographic processes that generate patterns of inequality. Thus qualitative designs offer the superior method to researching the processes behind environmental inequalities, as quantitative designs are limited in their explanatory power. Specifically, quantitative measures are unable to effectively capture historical processes behind environmental inequalities; such as real estate dynamics and land-use zoning laws (Holifield 2001).

In an attempt to battle the limitations of statistical analysis described above, some quantitative studies provide a [literature-based] historical context for their results (Szasz and Meuser 2000; Krieg 1995). However, these studies only offer the historical account from a textual perspective, failing to incorporate localized knowledge from key community informants. Lambert, Guyn and Lane (2006) take this approach a step further with a mixed methods design that incorporates interviews from local residents as well as 
statistical measures for a deeper and more sophisticated analysis of environmental inequality in the area studied. The authors explain that the mixed methods were:

designed to complement each other and...[support] the proposition that local knowledge adds contextual meaning that complements the physical measurement of environmental contaminants... and the multiple exposure pathways through which they can be affected. (P. 471)

Lambert et al. (2006) point to Corburn's (2002) criticism of traditional quantitative environmental justice research which effectively ignores localized "nonexpert" knowledge. Corburn argues that community knowledge is critical for understanding patterns of environmental inequality. Lambert et al.'s (2006) mixed method study finds that the local knowledge [data] matches both the statistical analysis as well as historical research. Thus, their research suggests that a mixed methods design is the best way to begin to fully account for and explain environmental inequality in a given region.

As researchers continued to find associations between toxin exposure and minority or low-income status, many scholars began to ask what came first: "[the] chicken or [the] egg?" (Bullard et al. 2008:373). Are hazardous sites placed in longstanding low-income and minority neighborhoods? Or do impoverished and minority communities surrounding toxic sites come into existence after the siting of the facility? Several studies confirm that disproportionately high concentrations of nonwhite and impoverished residents lived near hazardous facilities at the time of siting (Bullard et al. 2007; Saha and Mohai 2005; Pastor, Sadd and Hipp 2001). 
Despite what the aforementioned research suggests, environmental inequality processes are not a simple one-way path. Crowder and Downey's (2010) study on interneighborhood migration and pollution exposure offers some deep insights into this phenomenon. Their research demonstrated that African Americans were significantly less likely than whites to move away after industrial pollution begins or increases in their neighborhood. Ultimately, the study concluded that elevation of industrial pollution levels had no effect on outward mobility for African American residents. Moreover, Latinos and African Americans moved into significantly more polluted neighborhoods than their white counterparts, with Asians moving into neighborhoods with slightly lower pollution levels than whites. Income exhibited a similar association, suggesting that "higher-income movers are apparently better able than lower-income movers to gain access to less hazardous neighborhoods" (p. 1141). While these results cannot prove it, it is not unreasonable to conclude that minorities may also be disproportionately moving to hazardous neighborhoods after facility siting as well.

Overall, governmental response to environmental inequality concerns has been marginal at best (Bullard et al. 2008). Nevin Cohen's (1997) study on governmental attitudes towards environmental concerns sheds light on this problem. Not only were governmental officials (both state legislatures and their key staff members) skeptical about the toxicity and danger of chemical pollution, but only half of those surveyed believed that people of color share a disproportionate burden of environmental hazards. Furthermore, a considerable percentage responded "don't know" on the environmental inequality question, suggesting they were either ignorant of environmental justice issues 
or that they believed there to be conflicting evidence. Unsurprisingly perhaps, conservatives were more likely to deny the existence of environmental justice concerns than both liberals and moderates (Cohen 1997).

\section{Environmental Inequality in Portland, Oregon}

Many environmental inequality studies are centered on specific communities. The Portland, Oregon metropolitan area - the focus of this study - is a somewhat understudied city within the broader area of this scholarship. With bike lanes, efficient light rails, and public parks sprawling all over the city, Portland routinely wins prestigious awards as one of the "greenest" cities in the United States (Shandas and Messer 2008). Considering Portland boasts one of the cleanest environments in the nation, any instances of environmental inequality would offer interesting insight into (and ultimately challenge) the city's green reputation.

Smith (2009) and Downey (2006) both explore inequitable hazard exposure in the Portland area. ${ }^{3}$ Both studies conclude that racial environmental inequality was evident in Portland. Downey assesses the unique inequitable distribution of environmental hazards in 14 of the largest metropolitan areas in the U.S., Portland included. Using tract level census data and the EPA's Toxic Release Inventory (TRI) from 2000, Downey finds a positive association between percent Hispanic and average toxic emissions. Simply put, Portland neighborhoods with higher concentrations of Hispanics have significantly higher levels of toxins present. Downey also finds a curvilinear relationship between percent black and average emissions (which is captured by the inclusion of percent black squared in his regression models); the relationship is positive until the turning point of $23.61 \%$

\footnotetext{
${ }^{3}$ Smith's (2009) analyses are discussed in more detail in the following Superfund Sites section.
} 
black, thereafter increases in percent black are associated with decreased average

emissions. Pointing to Small and Newman (2001) and Wilson (1987), Downey explains that:

the urban poverty and spatial mismatch literatures suggest that there is relatively little industrial activity in extremely poor, highly segregated, urban minority neighborhoods. Thus, it is possible that industrial environmental hazards tend to be located in neighborhoods with high percentages of minorities, but not in neighborhoods with the highest percentages of minorities (P. 32)

Environmental inequality and health disparity concerns are a controversial topic in the city of Portland and have received a fair amount of attention from various local government and nonprofit entities. A recent report from the Oregon Department of Environmental Quality (2011) found that census block groups with higher percentages of Hispanics, African Americans, Asians, and families below the poverty line are associated with elevated levels of a variety of air toxins. Portland nonprofit Coalition for a Livable Future's (2007) Regional Equity Atlas provides a rich insight into several environmental health disparities that afflict the city. The study concluded that many of Portland's poor and minority neighborhoods suffer from a variety of public health concerns, including lack of access to healthy foods, elevated asthma rates, limited sidewalks and poor "walkability."

The Urban League of Portland (2009) produced a similar research report, entitled State of Black Oregon, which extensively outlines the health and economic disparities 
that African American Oregonians (particularly Portland residents) face. ${ }^{4}$ In addition to the stark contrast in asthma rates, the report concludes that a variety of health disparities plague Portland's African American residents. Infant mortality and low birth weights are 50\% more likely for African American than whites. African Americans also have higher rates of diabetes, high blood pressure, physical disabilities, and stroke, diabetes, heart disease, and cancer deaths.

Furthermore, intense economic inequities (which undoubtedly contribute to and magnify health disparities in the area) are omnipresent in Portland's socioeconomic landscape. For example, median income for white households is $50 \%$ higher than that of African Americans. African Americans are also less represented in Portland's labor force, faring 9 percentage points worse than white males and $6 \%$ less than white females. An alarmingly high number (38\%) of Portland's African American children live below the poverty line, with $60 \%$ living in households with income below $200 \%$ of the federal poverty level. African Americans are overrepresented in low paying fields (office administration, service occupations, transport and production) and are underrepresented in local living wage jobs (such as construction, extraction, maintenance, management professional occupations, sales and retail, and forestry). In addition, only $37 \%$ of African Americans own their homes, while $68 \%$ of whites are homeowners (Urban League of Portland 2009).

\footnotetext{
${ }^{4}$ The State of Black Oregon includes all of Oregon's African American residents in its study. However, the results are primarily concerned with Portland's African Americans as $80 \%$ of all blacks in Oregon reside in the Portland metropolitan area (Urban League of Portland 2009). Accordingly, I attribute the results reported in State of Black Oregon specifically to Portland residents; however, it is important to remember these numbers reflect the broader African American population of Oregon as well.
} 


\section{Superfund Sites}

Superfund sites - the indicator of environmental hazard used in this study - offer a tangible and quantifiable source of toxin presence for environmental inequality researchers. The federal government's Superfund program can be attributed to a single incident: Love Canal, an archetypal case of egregious governmental and corporate neglect for human and environmental health. From 1942 to 1953 the Hooker Plastic and Chemicals Company illegally dumped more than 20,000 metric tons of industrial chemical waste into the partially completed Love Canal in suburban Niagara Falls, New York (Harper 2004). By 1953 Hooker had covered the toxic canal with clay and subsequently sold the land to the local school board for a single dollar. The deed disclosed that "the premises above described have been filled, in whole or in part, to the present grade level thereof with waste products resulting from the manufacturing of chemicals" and dissolved Hooker of any liability thereafter, including deaths from exposure to the dumped chemicals (Zuesse 1981). However, this did not stop the city from building an elementary school and adjacent housing units directly on top of the covered dump. Two decades later the blue collar community surrounding the defunct canal became increasingly overwhelmed with an omnipresent odor, skin irritation (in both humans and pets), and disproportionately high rates of cancer, birth defects, and miscarriages. Lethal chemicals even began oozing up through the ground into home basements and the elementary school built on the site (DePalma 2004; Harper 2004).

Ultimately, the toxic waste that the community was built over was linked to the alarming health hazards that afflicted local residents. After considerable denial Hooker 
executives confirmed that they had used Love Canal as an illegal dumping ground for more than 80 different industrial chemicals. Love Canal, and the media frenzy surrounding it, brought the previously disregarded issue of toxin exposure into the public eye (Szasz 1994). In reaction to the atrocity, President Jimmy Carter declared the entire community to be federal disaster area and consequently relocated all the remaining residents. Accordingly, the federal government responded to the Love Canal debacle with the passing of Comprehensive Environmental Response, Compensation, and Liability Act (CERCLA), also known as the Superfund (DePalma 2004; Harper 2004).

Since its inception in 1980, CERCLA has served as a governmental watchdog for environmental health; successfully cleaning up hundreds of toxic industrial sites (of the roughly 32,000 sites that have graced the Superfund list) over the last three decades. ${ }^{5}$ The Superfund, managed and overseen by the EPA, tracks thousands of hazardous industrial sites around the U.S. and then plans and implements their cleanup (U.S. Environmental Protection Agency 2010a). This is a long and costly process; Love Canal alone took 21 years and around $\$ 400$ million to clean (DePalma 2004).

Sites that are deemed particularly toxic are placed on the National Priorities List (NPL) and are resultantly given the top priority in cleanup procedures. NPL status is determined by exceeding 28.5 on the Hazardous Ranking System (HRS) which quantifies "[1] likelihood that a site has released or has the potential to release hazardous substances into the environment; [2] characteristics of the waste (e.g. toxicity and waste quantity); and [3] people or sensitive environments (targets) affected by the release" (U.S.

\footnotetext{
${ }^{5}$ CERCLA was passed in 1980, but the Superfund was not actually functioning until 1983.
} 
Environmental Protection Agency 2011a). ${ }^{6}$ The EPA identifies four pathways that can be scored in the HRS: ground water migration, surface water migration, soil exposure, and air migration. As of October $25^{\text {th }} 2011,354$ of the 1,652 sites ever placed on the NPL have been cleaned and removed from the list (U.S. Environmental Protection Agency 2011b), with 900 or so substantially completed (DePalma 2004).

Due to the egregious cleanup costs, CERCLA mandates that the companies responsible for the contamination pay for the cleanup process (DePalma 2004). The act also included a "polluter pays" tax provision in order to finance cleanup of "orphan sites," or sites in which no particular [or existing] company can be linked to the pollution (Jacobson 2009). Since about 30\% of Superfund sites are orphans (Jacobson 2009), the polluter pays tax requires oil and chemical companies to pay an additional yearly tax in order to "ensure that parties who benefit from the manufacture or sale of substances that commonly cause environmental problems at hazardous waste sites, and not taxpayers, help bear the cost of cleanup when responsible parties cannot be identified" (U.S. Environmental Protection Agency 2010c). However, these taxes expired in 1995 and were successfully blocked for reinstatement by the Bush administration (Jacobson 2009; DePalma 2004). Despite Obama's campaign promise, a bill recently introduced in the Senate, and a congressional plea from the EPA, the polluter pays tax has yet to be reinstated and likely will not during Obama's first term (Taylor 2011; U.S. Environmental Protection Agency 2010c). In the meantime, U.S. taxpayers will continue to foot the bill for cleanup of all orphaned Superfund sites.

\footnotetext{
${ }^{6} 2$ Also, each state and territory is allowed to place one site of its choosing on the NPL regardless of HRS score (U.S. Environmental Protection Agency 2011c).
} 
Needless to say, Superfund sites pose considerable danger to surrounding human populations and ecosystems. Various Superfund sites have been linked to a gamut of health hazards in adjacent communities, such as immunity deficiencies (Williamson et al. 2006), lead poisoning (Sterling et al. 2004), and cancerous toxins (Karouna-Renier et al. 2007), and many more. Unfortunately, research has shown that physicians who practice in communities which house Superfund sites (and similar well known toxic waste sites) are just as ignorant of environmental health hazards as physicians in non-toxic areas (Brown and Kelley 1996). Of all people, one would assume that doctors would be quite knowledgeable of local environmental health issues. However, Brown and Kelly (1996) reason that their research suggests that many doctors lack a public health lens. However, the authors explain that the lack of a public health focus amongst doctors may also be attributed to reluctance to take a stand on such politically and economically controversial issues as the siting of Superfund sites and other industrial facilities.

Superfund sites have been applied as an indicator of toxic hazard in a multitude of environmental inequality studies (Sicotte 2010; Smith 2009; Noonan 2008; Baden et al. 2007; Baden and Coursey 2002; Hird and Reese 1998; Stretesky and Hogan 1998). Most of these studies found race and income to both be significant predictors of Superfund site presence, concluding that the poor and people of color are disproportionately represented in areas near Superfund sites (Sicotte 2010; Smith 2009; Noonan 2008; Baden et al. 2007; Hird and Reese $1998^{1}$ ). Intriguingly, Hird and Reese's (1998) analyses actually found that income had a positive relationship with pollution levels (however, Superfund sites were only one component of their environmental quality dependent variable). 
Conversely, the significance of race and class were not the case in all Superfund studies. Demonstrating the methodological variations inherent within the literature, Stretesky and Hogan (1998) found race to be the sole significant predictor of Superfund site presence, while Baden and Coursey's (2002) analyses conclude it to be income.

In addition to the inequitable distribution of Superfund sites, research has shown cleanup to be markedly unequal when comparing the demographics of remediated areas. Lavalle and Coyle (1992) found that Superfund cleanup efforts in communities of color took significantly longer than that of predominantly white communities, even though the remediation process in minority neighborhoods was generally less intensive than needed in the white neighborhoods studied. This study also found that the average fine for polluters in predominantly white areas was over 500 percent higher than the fines associated with polluting in minority communities (Lavalle and Coyle 1992). And despite an executive order from President Clinton mandating that the EPA address environmental justice concerns, research has also shown that hazardous sites in minority and impoverished communities are significantly less likely to be selected as Superfund sites by the EPA; contributing to perpetual toxicity in these areas (O'Neil 2007). Similarly, relocation packages offered to residents of white neighborhoods that were being remediated have been considerably better than those offered to African American communities (Lerner 2010).

The slow pace of cleanup in minority communities is increasingly suspect when one considers Petrie's (2006) study. In her study of Superfund remediation processes throughout eight southern states, Petrie (2006) finds that remediation takes considerably 
longer when communities are actively involved in the process; concluding that the presence of community meetings and deliberation causes a slower cleanup process. However, her study finds that communities of color are significantly less likely to get involved in the cleanup process, which may be attributable to the exhibition of distrustful attitudes towards the EPA amongst minorities. Considering Petrie's (2006) findings, the inequities associated with the slower pace of remediation in communities of color are considerably magnified.

Smith's (2009) environmental inequality study looked specifically at Portland (and Detroit) Superfund sites. Using 1990 census data and 2000 EPA Superfund site records, Smith analyzed the association between black/white racial segregation and economic deprivation as they relate to Superfund site presence at the census tract level. At the bivariate level, ${ }^{7}$ Smith concludes that Portland "tracts with Superfund sites have a statistically significant higher percentage of Blacks and a statistically significant greater amount of economic deprivation when compared to tracts without Superfund facilities" (p. 686). However, the significance of race disappears in his subsequent logistic regression models. The logits analyze black/white segregation (measured by a dissimilarity index) instead of percent African American (which was used in the bivariate analysis), and neither model concludes this variable to be significant.

Model 1 in Smith's (2009) study tests the relationship between black/white segregation and Superfund site presence, while controlling for population density, urban

\footnotetext{
${ }^{7}$ Two-sample t-test with equal variances.
} 
tract status $^{8}$ (dummy variable where urban tracts $=1$ and suburban tracts $=0$ ), and median housing value. Only population density demonstrates a significant coefficient in Model 1. Model 2 adds an economic deprivation index (composed of percent living below the poverty line, percent unemployed, percent of female-headed households, percent receiving welfare, percent without a high school diploma, percent employed as an executive, and median income) to the logit. Ultimately, population density and economic deprivation are the only significant predictors of Superfund site presence in Model 2; suggesting that Superfund sites are more likely to be found in less dense and more economically deprived tracts.

Even though Portland has considerably fewer Superfund sites than historically industry-heavy cities (such as Detroit, see Smith 2009), numerous hazardous sites are still located in the Portland metro area. The Portland metro is divided by three county boundaries: Clackamas, Multnomah, and Washington counties. Clackamas County has 62 census tracts, six of which contain seven Superfund sites. Multnomah County contains the city center, the urban core, and the bulk of the industrial activity for the tri-county area. Accordingly, Multnomah County has the most Superfund sites with 29 sites in 10 of the 170 tracts in the county. ${ }^{9}$ Washington County has only two Superfund sites in two of its 81 census tracts (U.S. Census Bureau 2001; U.S. Environmental Protection Agency 2010b). The types of facilities designated as Superfund sites are relatively diverse in the Portland metropolitan area, including some which are no longer open or operating.

\footnotetext{
${ }^{8}$ Data for this variable comes from historical documents from the U.S. National Archives and the variable was created manually using GIS software.

${ }^{9}$ Both Clackamas and Multnomah counties have a Superfund site that is not attached to a single census tract. Each of these is accounted for in the numbers listed above, but is not included in the quantitative analysis. See data and methods for a more detailed explanation.
} 
Examples include shipping/port industry facilities, landfills, polluted water ways, and a mine. The types of dangerous pollutants that emanate from Portland area Superfund sites are similarly varied; the EPA reports that cyanide, PCBs, pesticides, and oil exemplify some of the problematic pollutants in the metro's Superfund sites (U.S. Environmental Protection Agency 2010b).

\section{Portland, Oregon: A Legacy of Inequity}

Portland's [racial] history is a unique one and the historical context is critical to understanding the results presented in this thesis (Pellow 2000; Pulido et al. 1996). In 1845 a coin was flipped and "Portland" was subsequently chosen as the name for the small settlement in Oregon Territory nestled next to the Willamette River (Lansing [2003] 2005). From the very beginning, African American Portlanders experienced intense barriers to social, physical, and economic well-being. In 1844 Oregon territory passed laws that not only prohibited slavery but forbade African Americans from living, working, voting, or owning property in Oregon; effectively attempting to establish a racially pure territory (Urban League of Portland 2009). These laws continued to be enforced for the first few years of statehood as well. However, other discriminatory laws persisted for much longer, such as an interracial marriage ban that lasted until 1955. Jim Crow-esque policies were prevalent until the civil rights legislation of the 1950s and contributed to intense economic and housing segregation amongst African Americans in the area. Partly as a result of this extreme legal discrimination, African Americans constituted a very small portion of the Portland population until the beginning of the Second World War. 
Following the United States entry into WWII, the federal government sought to dramatically increase its production of ships (Maben 1987). Portland stepped up to the challenge and quickly became the nation's biggest producer of Liberty cargo ships. The City of Roses was subsequently flooded with thousands of African American laborers who came to work in the shipyards. In the years of 1940-1943, Portland's African Americans population exploded from roughly 2,500 to more than 20,000 (Urban League of Portland 2009). A dramatic housing shortage ensued, and plans were quickly crafted to create the largest wartime housing project of the time (Lansing [2003] 2005). The result was Vanport City. Built on a known flood plain on the Columbia River, Vanport ultimately grew to over forty-two thousand residents. Nearly all African American wartime housing applicants were placed in Vanport. Not only did Vanport represent racial segregation on a city-wide scale, but African Americans were segregated within the project as well. African Americans applicants were purposely assigned to housing in certain adjacent sections of Vanport which had the intended effect of concentrating the newly arrived African Americans masses in a densely populated sector of the project (Maben 1987).

While a considerable number of white residents fled, many African Americans stayed in Vanport after the war was over, solidifying the project as a symbol of a segregated African American community (Maben 1987). Mass layoffs also followed the war's end, and thousands of Vanport residents were suddenly in need of work outside the shipyards. African Americans were hit particularly hard as prevailing racial biases of the time prevented many of them from finding other jobs. These economic hardships 
drastically inhibited the mobility of Vanport's African Americans residents, forcing most to stay in the segregated area.

On the morning of May $31^{\text {st }}, 1948$ notes were slipped under Vanport residents' doors that informed them that they were safe and that, despite the elevated river level, a flood was not currently likely (Maben 1987). Contrary to the consolation, later that afternoon the city of Vanport experienced a flood of biblical proportions and was wiped into oblivion. Only fifteen fatalities were recorded and seven others were never found and presumed to be deceased. Adding insult to injury, all of Vanport City's residents were suddenly homeless. This presented a considerable challenge for the five thousand or so African Americans that were displaced from the flood, as Vanport was one of two areas that they were primarily permitted to live in.

While African American wartime housing project applicants in the 1940's were shuffled into Vanport City, real estate agents simultaneously pushed soon-to-be African American homeowners into North/Northeast Portland's Albina district (Abbott 2001). Realtors were trained to show African Americans homes only in the Albina area and brokers were subject to losing their license if they violated this rule. Thus, the majority of Vanport's displaced African American residents were forced to move into Albina, which contributed to overcrowding in the area at the time (Lansing [2003] 2005). Karen J.

Gibson (2007) explains how these real estate practices further exacerbated the economic disparities facing African Americans:

Critical to the process was the systematic denial of mortgage capital, which was justified by appraisals that devalued African American neighborhoods. In addition, predatory lenders, speculators, and 
slumlords played a strong role in keeping Albina residents from accumulating wealth through home ownership and, in some cases, cheated residents out of their equity investments and earnings. Since home ownership is the most common form of wealth, this helped to perpetuate economic inequality in Portland. (P. 6)

Over the next several years, Portland's African American community would stretch a mile north (Abbott 2001). Unfortunately, this area would be marked by intense social and economic problems. By the early 1980's, gang warfare, crack cocaine, prostitution, housing abandonment, and economic stagnation defined the larger Albina area (Gibson 2007). Accordingly, Albina home values plummeted to 58 percent of the median for the city. However, the 1990's witnessed a surge of "urban renewal" projects and Portland's African American neighborhoods would soon experience a dramatic reorganization. During this decade the city of Portland and realtors alike put considerable effort into revamping the Albina district. The "Alberta Arts District," for example, was aggressively marketed to Portlanders and was subsequently linked to a massive influx of white residents to the area (Sullivan and Shaw 2011; Shaw and Sullivan 2011). Slowly, many of the African American owned businesses in the area began to close shop. Similarly, the once low housing values quickly shot-up, displacing many of the lowincome African American residents to distant and remote parts of the metro where they could afford housing (Gibson 2007).

This process of gentrification significantly changed the racial and economic makeup of Albina. Gibson (2007) explains:

By 1999, Blacks owned 36 percent fewer homes, while Whites had 43 percent more than a decade 
earlier....The White home ownership rate escalated from its rock bottom of 44 percent to 61 percent in just ten years. Housing values, as a percentage of the city median, rose significantly, from 58 percent to 71 percent. This sharp rebound in Albina property values, which corresponds with the increase in White home ownership, reveals the continuing correlation between property valuation and race. (P. 21)

Environmental injustice is a significant feature of the social and economic disinvestment in the Albina community (Collin 2008). A considerable number of Portland's approximately 500 brownfields are located in Albina. Brownfields, albeit generally less toxic, are similar to Superfund sites. Like the Superfund, brownfield remediation programs serve to designate and clean up hazardous sites; enabling the community to safely access and use the space (Collin 2008). Countless of Albina's brownfields are perpetually in assessment limbo, as many have been deemed potentially hazardous by environmental officials but have yet to be assessed (Collin 2008). Collin notes that, without an assessment, these properties continue to be "unclean, untaxed, and unproductive" hazardous sites (p. 438). Albina has experienced some successful brownfield remediation over the years, but significant numbers remain.

As the home of the Albina district, North/Northeast Portland is a diverse area which houses a considerable amount of the city's African American population. Unfortunately, it is also may be the most toxic. Collin (2008) notes that this is a region "where the largest concentrations of abandoned industrial and commercial sites exist contiguous to residential areas. It is an area heavily impacted by traffic and air pollution. 
This area has the largest proportion of pre-1950's housing stock in the city of Portland" (440-441).

From segregation to gentrification to displacement, Portland African Americans have been marginalized and disenfranchised from the beginning (Sullivan and Shaw 2011). While Portland's African American history tends to stand out, other ethnic and racial minorities (such as Asians and Latinos) have also had struggles in the largely white city and have been prone to similar processes of segregation and displacement (Abbott 2001). In addition to Portland's legacy of racial segregation, it is important to note the socioeconomic dynamics present as well. Poverty is problematic across ethnic lines in the Portland metro region. While large numbers of minorities struggle with poverty, "Portland poverty is largely white" (Abbott 2001:99). And despite the economic inequities present in Portland's minority neighborhoods, the city lacks any racially isolated ghettos like that of Chicago or New York. Outlining Portland's longstanding struggle with segregation and poverty is helpful to properly understand the unique context of environmental inequality studied in this thesis (Pellow 2000; Pulido et al 1996).

\section{Environmental Inequality Formation}

Despite the extensive catalogue of environmental inequality research, the massive body of literature is largely atheoretical (Pellow 2000). Instead of pursuing a theoretical approach, most of these studies fail to analyze their results within a broader sociological framework. Consequently, much environmental inequality research focuses solely on whether or not minority and low-income communities are disproportionately burdened by 
toxins (and overwhelmingly does so through cross-sectional quantitative approaches) (Pellow 2000). Essentially, the bulk of these studies only explore if environmental inequality is present while effectively (or blatantly) ignoring how this process has taken place (Holifield 2001; Pulido et al. 1996).

In an attempt to remedy the theoretical and methodological deficiencies of environmental inequality research, David Pellow (2000) proposes a sophisticated theoretical model - called the "Environmental Inequality Formation" perspective (or, EIF) - that seeks to explain the complex processes which underlie environmental inequality. Pellow refuses to reduce environmental justice struggles to simple "perpetrator-victim scenarios" which contend that "environmental inequalities occur when the poor or people of color are dumped on or exposed to hazards because they are less powerful than corporations and the state" (Pellow 2000:587). He notes that while much of this reasoning may often be correct, it is nevertheless "overly simplistic and ignores important details, the role of key players, and significant variability across different cases" (Pellow 2000:587).

Pellow argues that environmental inequality is a more complex process than the oft used perpetrator-victim scenario and that the formation of the injustice should be the focus of research on the topic. Noting that no two environmental justice struggles are the same, Pellow proposes a tripartite framework to help explain the formation of environmental inequality for a given area. Thus, in order to account for and explain the formation of environmental inequality, the EIF perspective stresses the importance of: 1) process and sociohistory, 2) the roles of numerous stakeholders, and 3) a life-cycle 
conceptualization of production/consumption and associated hazard exposure (Pellow 2000). By examining the broader sociohistorical background behind environmental inequality, acknowledging the interest and motivations of the various stakeholders implicated in that process, and approaching environmental inequality from a life cycle perspective, researchers are able to embed environmental inequalities within the context of greater social forces (Pellow 2000).

\section{History and Process}

Following on the heels of Laura Pulido's work (Pulido et al. 1996; Pulido 1996), EIF utilizes a historical approach to environmental inequality research. In the following excerpt, Pellow (2000) explains why it is critical to understand the sociohistorical processes at play:

The EIF - environmental inequality formation perspective stresses not only understanding how environmental inequalities unfold but also actually defining environmental inequality as a process hence, my choice of the word formation rather than simply environmental discrimination.

Reconceptualizing environmental inequality as a process changes the whole framework for theory, methodology, and policy because it is difficult to explain, measure, and develop policy around a process that is not reducible to a discrete set of actions. (P. 588)

Since the path to environmental inequality is not a simple one-way street, it is important to extensively assess the historical processes that have contributed to the current state of inequity. Thus, framing environmental inequality as a process allows researchers to effectively analyze how environmental inequalities are created and flourish, instead of simply evaluating their mere existence. Pellow (2000) concludes that 
"[t]his is important because without an adequate understanding of how environmental inequalities are produced, our theories about why and how people suffer from them remain inadequate" (p. 592).

There are a variety of qualitative methods that are appropriate for researching the historical process of EIF, with ethnographic and historical analysis being two of the better ones (Pellow 2000). Pellow's (2000) initial EIF article, as well as his book Garbage Wars (Pellow 2002), both offer extensive historical accounts of environmental justice struggles connected to waste processing facilities. Looking at environmental inequality processes in the homes and workplaces of low-income and minority communities over several generations, these studies provide a rich sociohistorical account of the events that contributed to and shaped current environmental justice issues. The end result of this historical approach is an increasingly nuanced understanding of how environmental inequalities are produced, affording researchers the methodological and theoretical tools needed to effectively answer "chicken or egg" questions around hazardous facility siting and residential migration (Puldio et al. 1996).

\section{Multistakeholder Reality}

Since environmental inequality is not the discrete set of actions that perpetratorvictim scenarios purport, it is important to account for the roles of multiple stakeholders when studying EIF processes (Pellow 2000). Pellow (2000) observes that traditional models that simply claim that corporations pollute neighborhoods that lack the power to challenge the injustice are inadequate. He develops a more sophisticated theoretical perspective that argues that "when one studies environmental inequality from a 
multistakeholder perspective, it becomes clear that environmental inequalities are not always simply imposed unilaterally by one stakeholder on another" (p. 592). Conversely, environmental inequality is an ongoing process that involves the complex interests, conflicts, relationships, and negotiations among numerous stakeholders. Given that EIF is not a simple linear process, Pellow (2000) notes that the interests and actions of stakeholders are quite complex and subsequently "may often appear contradictory, and can shift over time" (p. 592).

Who are these stakeholders and what do they want? Keeping in mind that the intricacies (and thus stakeholders) of environmental justice issues vary across time and space, stakeholders are the various actors, organizations, and institutions that have vested interests in the struggle and are actively involved in some aspect of the environmental inequality process (Pellow 2000). These stakeholders take a variety of forms; employees, residents, businesses, government, and social movement organizations exemplify some of the more common stakeholders in environmental hazard conflicts.

This multistakeholder approach allows researchers to move away from unrealistic unitary conceptualizations of racism and classism that are often relied upon in environmental inequality studies (Pulido et al. 1996). For example, a significant quantitative association between race and pollution levels (while important) is unable to effectively capture the dramatic social and historical forces at play (Pellow 2000; Pulido et al. 1996). Something as complex as "racism" cannot simply be analyzed and understood with solely quantitative measures. Furthermore, racial categories are not as fixed as traditional environmental inequality studies may make them seem (Pulido et al. 
1996). Thus, EIF's historical approach to a "multistakeholder reality" (Pellow 2000:592) allows researchers to unpack the motivations and behavior of the various entities involved in the intricate process of a given struggle, instead of reducing it to something as unrealistically simple as "poor African Americans vs. the racist corporation."

EIF's multistakeholder framework offers researchers a much needed theoretical mechanism to understand the process of environmental inequality formation. Pellow (2000) contends that environmental inequality is a manifestation of stakeholders' struggles for access to the gamut of resources that are valued in society. Thus, environmental inequalities are formed when various stakeholders compete for these resources and the benefits and burdens of said resources are distributed unevenly. If stakeholders are incapable of effectively mobilizing resources they are likely to experience environmental inequality. On the other hand, stakeholders with greater access to valued resources are able to deny other stakeholders from accessing them (Pellow 2000).

Therefore, the situation is vicious cycle of sorts; not only do stakeholders suffer from environmental inequality due to their inability to successfully marshal resources, but they are also actively deprived of these societal resources by more privileged and powerful stakeholders. This is because those with the greatest access to resources tend to hoard them and fail to relinquish any to those who lack them. This circular model is particularly detrimental for marginalized stakeholders, as it perpetuates environmental inequality by preventing those who suffer from ever ameliorating the situation. Pellow (2000) notes that these "resources" appear in a variety of forms; with status, power, and 
wealth being some of the more influential examples. Additionally, EIF also

conceptualizes access to safe and clean living, working, and recreational environments as critical resources. Pellow (2000) notes that resources are often interrelated and describes an inverted relationship for the disparity in stakeholders' access:

Thus, the inability to access these resources often means living and working under dangerous conditions, with very little power, wealth, or status. Conversely, those stakeholders with the ability to access these resources live and work under safer, healthier conditions with more power, wealth, and status. (P. 589)

Considering that the interests of stakeholders are not always diametrically opposed and may actually intersect at times, stakeholders on opposite sides of an environmental struggle may sometimes work together for a "win-win" outcome that aims to benefit all (or at least most) of the parties involved (Pellow 2000:589). This cooperative approach to solving environmental hazard issues is known as "collaborative framing” (Pellow 2000; Pellow 1999). As opposed to “oppositional framing," collaborative frames are "produced jointly by activists who collaborate and struggle with their opponents" (Pellow 1999:664). Pellow (1999) contends that a collaborative framework "represents a shift in strategies and tactics on the part of environmentalists who draw upon both the political economic and environmental justice frames to produce this new model of struggle" (p. 664).

However, even supposed win-win scenarios stemming from collaborative framing approaches can have unintended environmental inequality consequences. Pellow's (2000) case study of a Chicago waste processing facility offers a prime example of an 
environmental justice struggle that was actually birthed by a collaborative frame which was supposed to benefit the environment, local human health, and business and governmental interests all at once. In the mid 1990's, Chicago embarked on a massive plan to institute a city-wide recycling program and consequently to build a new recycling plant that would replace the toxin spewing incinerator that the city previously relied on for waste management. Under a collaborative framework, this policy embodied the intersection of numerous competing interests. "Community organizations supplied much of the willing labor, environmentalists provided the ideological foundation for recycling, and the state offered financial and political support" (Pellow 2000:589).

Despite the altruistic motives behind the plan, a significant environmental justice struggle ultimately emerged from the recycling policy. While the new WMI recycling facility offered an abundance of jobs to African-American laborers, the jobs came with some egregious caveats. Pellow (2000) describes the dangerous and exploitive working conditions of the overwhelmingly African American staff of low-wage laborers:

Many of the workers informed me that, while sorting through garbage and recyclable waste on the job, they were accidentally stuck by used hypodermic needles; had to frequently handle medical waste; were sprayed with battery acid, paint thinner, inks, and dyes; and were exposed to dead human and animal bodies on a periodic basis. Moreover, management's treatment of employees included, to quote one manager, "keeping our foot in the worker's ass," forced overtime with shifts up to 20 hours per day, failure to pay employees, and arbitrary firings. (P. 583)

This example shows how collaborative frames can occasionally backfire and produce new and unintended environmental justice conflicts. If collaborative frames do 
not consider the interests of all parties, particularly marginalized stakeholders with limited access to resources, inequitable outcomes may be a consequence of the action. Pellow (2000) explains that the collaborative frame ultimately perpetuated the environmental inequalities it created: "[t]his apparent consensus among key stakeholders produced a situation that made it difficult to illuminate the problem of occupational hazards in the WMI facility" (p. 589). Thus, while collaborative frames can offer successful strategies for challenging environmental hazards, they may also simultaneously create and exacerbate local environmental justice issues.

\section{Life-Cycle Analysis}

The third and final component of EIF is a life-cycle orientation towards environmental damage and hazards (Pellow 2000). Most environmental hazard studies are solely concerned with pollution and other dangerous "additions" to the environment, and consequently neglect the egregious ecological damage that takes place during the entire life-cycle of production to consumption (Schnaiberg 1980). Alternatively, the EIF perspective contends that researchers must look beyond pollution and consider the entire life-cycle (natural resource extraction, processing through production, distribution, consumption, and disposal) when studying environmental justice conflicts (Pellow 2000). Diverging from traditional ecology-centric models of life-cycle analysis, "an EIF approach to life-cycle analysis would involve an accounting of the social, economic, and ecological impacts of production and consumption" (Pellow 2000:595).

Life-cycle analysis allows for a deeper and broader understanding of environmental inequalities, "[b]ecause people and ecosystems are affected at every point 
along the production-consumption continuum" (Pellow 2000:595). Within this framework, the scope of environmental inequality is dramatically broadened as researchers are able to look at the intersection of various environmental injustices. In his seminal EIF article, Pellow (2000) uses a life-cycle framework to dive deeper into the environmental justice issues that the recycling plant workers faced. The hazards that the workers encountered on a daily basis in the recycling plant can be linked to both job creation (a benefit) and ecosystem destruction around the world from the production of the materials that come to the facility (a cost). The waste - paper for example - that makes its way into the facility was once a natural resource (in this example, trees) that had to be extracted and refined before it could be used. From there, these products were manufactured into consumer goods that after distribution and consumption will ultimately be disposed of. Much - if not all - of this process involves socially repressive and environmentally hazardous practices. By analyzing the entire life-cycle of the recycled product, one can see how phrases like "green" or "clean" are misinformative and do not accurately describe the larger recycling process.

In a continuation of the life-cycle analysis of his Chicago case study, Pellow (2000) goes on to explain how there is a direct link between the frequent contact with dirty needles experienced by recycling plant employees and contemporary out-patient trends of hospitals. These examples serve to illuminate the importance of history and process behind environmental inequalities; life-cycle analysis is critical to fully understanding how environmental inequalities form. Furthermore, life-cycle approaches allow researchers to expand the scale of their understanding of environmental justice 
issues, as they are able to link social, economic, and ecological issues that more than likely would have previously gone unconsidered.

The Environmental Inequality Formation model provides a sophisticated method for how to conceptualize and address environmental inequality within a theoretical framework. By investigating the historical processes behind environmental inequalities, examining the various stakeholders involved, and understanding the larger life-cycle of environmental hazard exposure, researchers are able to assess environmental inequalities through a sociological framework (Pellow 2000). Considering that little scholarly attention has been paid to formations of environmental inequality and the lack of empirical work on the matter, this thesis is able to contribute to the discourse on environmental inequality as a process. Thus, this thesis serves to advance the theoretical conversation around environmental inequality and provides a critical next step to a better understanding of environmental justice struggles.

In addition to a quantitative analysis which analyzes if environmental inequality is present in Portland, OR (and who is most affected), the qualitative research presented in this thesis explores the structural and local forces that have contributed to environmental inequality in the region. Thus, Pellow's EIF perspective is an appropriate guiding theoretical framework for this thesis as it helps dismantle the underpinnings of Portland's environmental justice issues, by 1) requiring an extensive analysis of the relevant historical issues that have led to the current state of inequity, 2) allowing the research to look beyond the obvious parties involved and into the multitude of relevant stakeholders, and 3) incorporating a life-cycle understanding of environmental hazard exposure. All 
three of these components will prove to be critical to unpacking the structural and local forces which have shaped environmental inequality in Portland, and consequently will help guide the qualitative methods, analysis, and discussion.

\section{Research Questions and Hypotheses}

Despite the extensive literature on environmental inequality (and related phenomena) described above, there are still important research questions to be explored. Specifically, this research aims to contribute to the sociological conversation on environmental inequality by: 1) engaging the methodological debate by pursuing a much needed mixed-methods approach as well as comparing results to previous Portland studies, 2) researching the understudied Portland metropolitan area, and 3) not only analyzing if and what form of environmental inequality is present (as most studies do), but investigating how this process has taken place over the years in Portland.

Furthermore, this research aims to contest Portland's reputation as one of the most sustainable cities in the United States (Shandas and Messer 2008). Instances of environmental inequality found in this research not only challenge Portland's ecofriendly status, but expose the hypocrisy of a city that prides itself on being the archetype of a sustainable city. Cities that seek sustainability must not only strive for environmental quality, but must embrace "the institutions and processes that generate social health and well-being now and in the future" (Dillard et al. 2009:4).

Thus, the following research questions and hypotheses are proposed: R1) Are Superfund sites disproportionately located in tracts with higher concentrations of impoverished residents? 
H1) Superfund sites are disproportionately located in tracts with higher concentrations of impoverished residents.

R2) Are Superfund sites disproportionately located in tracts with higher concentrations of racial minorities?

H2) Superfund sites are disproportionately located in tracts with higher concentrations of racial minorities.

R3) What structural and local forces contribute to environmental inequality in Portland? 


\section{Data and Methods}

The research design employed in this study is a mixed methods approach which combines semi-structured in-depth interviews with key informants and stakeholders in Portland/Oregon's environmental justice movement with a quantitative analysis of 2000 census and 2011 EPA Superfund data. Data from four interviews and a logistic regression of the self compiled data set offer an extensive exploration of environmental inequality in Portland, Oregon.

\section{Analytical Strategy}

There are a variety of understandings and operationalizations of the concept of “environmental inequality" (Pellow 2002). Thus, it is important to lay out this thesis's orientation towards the concept. For the purposes of this research, environmental inequality "occurs when a particular social group - not necessarily a racial or ethnic group - is burdened with environmental hazards" (Pellow 2002:8).Furthermore, the conceptualization of environmental inequality is a broad one, as it could include "any form of environmental hazard that burdens a particular social group" (Pellow 2000:582). Under this framework, environmental hazards are understood not just as pollution exposure, but also any other "environmental bads," including (but not limited to): lack of green space, high rates of occupational hazards for poor and non-white workers, "unsafe and segregated housing," and even "neglect of human health and social justice issues by the established environmental movement" (Pellow 2002:9).

Broadly, this research serves to investigate environmental inequality in Portland, Oregon. The approach is twofold: 1) a quantitative analysis seeks to assess if 
environmental inequality is present and who is disproportionately burdened; and 2) semistructured in-depth interviews are employed to further assess local environmental inequality processes, to unpack the historical forces, and to identify the stakeholders that have shaped environmental inequality in the area. Since it is difficult to fully assess environmental inequality with quantitative measures (Pellow 2000; Pulido et al. 1996), the quantitative work presented here serves only as a proxy indicator of environmental inequality in the region. Even though Superfund sites represent only a small portion of environmental inequality issues in the Portland area, they offer an easily quantifiable source of hazard presence that reflects Portland's environmental history of industry, pollution, and inequity. Despite these inherent limitations (and also the inability to address historical processes), significant associations between environmental hazards, race, and poverty still offer important insight into environmental inequality issues (Pulido et al. 1996). However, qualitative methods are more appropriate for attempting to uncover the forces behind environmental inequality processes and consequently offer a more nuanced understanding of the phenomena (Pellow 2000; Pulido et al. 1996). Thus, mixed methods offer the most comprehensive approach for investigating environmental inequalities as the qualitative findings are able to strengthen the quantitative findings by providing a contextual meaning (Lambert et al. 2006). In sum: as the quantitative proxy exposes if environmental inequality is present and for which social groups, the qualitative research is able to reinforce these findings and also compliments them by adding contextual meaning; specifically by exploring how environmental inequalities are formed and maintained in Portland. 


\section{Quantitative}

Data

Environmental inequality in Portland is assessed by merging 2011 Comprehensive Environmental Response, Compensation, and Liability Information System data (hereafter CERCLIS) with 2000 census tract level demographic data. CERCLIS is the EPA's Superfund site database (a dataset in the EPA's Superfund Site Information System) which catalogs Superfund sites for a given area. After choosing the level of aggregation, CERCLIS retrieves the list of all Superfund sites in the chosen area and for each site offers their address (or location for sites with no address), cleanup status, and other information pertaining to the specific site. All census tracts within Multnomah, Washington, and Clackamas counties are included in the design in order to look at environmental inequality across the greater Portland metro area. Thus, the entire population of the Portland, Oregon metropolitan area is considered in the study. Even though the census data is from 2000 and the Superfund site data is from 2011, the two timeframes are still compatible within the same analysis as the sites have been sources of pollution for years. Many of Portland's Superfund sites have been around for generations, some of which have been out of business for many years (U.S. Environmental Protection Agency 2010b). Thus, the environmental hazards associated with 2011 Superfund designees were just as problematic in the previous decade (and may have been worse if remediation had yet to begin), making the combination of the datasets appropriate and valid. 
The area studied has 313 tracts and is currently home to 38 Superfund sites. However, only 18 of these tracts have Superfund sites as many of Portland's Superfund sites are clustered together within the same tract. Also, two Superfund sites were excluded from the analysis. One site - a mine - was not associated with a particular census tract as there were no residents for miles. The other site excluded is the Portland Harbor, which is essentially the stretch of the Willamette River that runs through the entire city center. This site is problematic as it is nearly impossible to determine which census tracts the harbor runs through given the non-graphical census and CERCLIS resources at the researcher's disposal; the online census database requires a physical address to ascertain a particular Superfund site's associated tract ID and the CERCLIS entry for this site only provides the river mile marker boundaries of the harbor. The final analyses have only 311 tracts, as two tracts were filtered out due to missing values on median housing value.

The data set was constructed manually using the following method. First, 2000 census data was downloaded from the U.S. Census Bureau's website (using the website's American FactFinder 2) for all the independent variables for Clackamas, Multnomah, and Washington Counties. Then the CERCLIS database was used to obtain information on all the Superfund sites in the target counties. These counties were chosen not only to account for the entire Portland metro, but also because they matched the 2000 census county level aggregation. The CERCLIS results offer detailed descriptions of all the Superfund sites for each county searched for. Some of the details include: site name, address, NPL status, specific toxins (for some sites only), and whether or not the site is a 
federal facility. The addresses provided for each site were used to search the online census database for their respective tract ID, enabling the creation of a Superfund site presence dummy variable. Some of the facilities had vague or no longer existing addresses and required further investigation on Google Maps to determine an approximate address that would account for the appropriate tract that the site was located in.

\section{Unit of Analysis}

All dependent and independent variables are at the tract level. Units of analysis are a contentious issue in environmental justice studies (see Noonan 2008 and Baden et al 2007). Baden et al. (2007) finds that the smaller the scale the more likely that logistic regressions will exhibit significant associations between Superfund sites and race or income; concluding that tract and block-group units demonstrate higher significance levels and coefficient magnitude than counties or zip codes. The analyses presented in this paper partly serve to re-evaluate Smith's (2009) and Downey's (2006) findings on Portland and subsequently employ the same tract level unit of analysis used in those studies. Furthermore, this researcher argues that census tracts are an appropriate unit of analysis as they are small enough to be associated with the localized environmental hazards which stem from Superfund sites. Conversely, it would be imprudent to use zip codes or counties as the unit of analysis, as the area would be too large to link relatively contained environmental hazards to the entire population. 


\section{Dependent Variable}

In order to update and compare the literature on Portland environmental inequality stemming from Superfund sites, the dependent and several independent variables are constructed similarly to Smith's (2009) study. The dependent variable seeks to measure proximity to dangerous environmental hazards and is operationalized by the presence of Superfund sites. For the purpose of this study, extreme environmental hazards shall be based off of EPA designations of excessive toxicity, and this is precisely what Superfund sites denote. Census tracts will be coded dichotomously; does the census tract have a Superfund site present? Yes (1) or no (0). There are virtually infinite ways to measure presence of environmental hazards (such as TRI data or presence of any hazardous waste facilities), but Superfund sites are highly valid and reliable indicators as they are scientifically and governmentally documented sources of toxic pollution. Even though they only measure proximity (and thus have varying levels of exposure and toxicity), Superfund sites nevertheless provide a strong basis for analyzing environmental inequality trends in metropolitan areas (Smith 2009).

\section{Independent Variables}

Independent variable operationalization is as follows. In order to consider the minority racial composition of a tract, percent [non-Hispanic] African American, percent African American squared, percent Hispanic, and percent [non-Hispanic] Asian of each census tract employed as independent variables. These three races are focused on as they constitute historically marginalized groups and represent three of the larger minority populations in Portland. The percent African American squared term is included in order 
to account for a non-linear relationship with the dependent variable (see quantitative findings section). Previous literature has shown that a curvilinear relationship often characterizes the association between percent African American and presence of environmental hazards (Downey 2006; Small and Newman 2001). Even though industrial areas (which generally house Superfund sites and other toxic facilities) may have considerable percentages of African Americans, they rarely are among the tracts with the highest percentages of African Americans in a city. Rather, the tracts with the highest concentrations of African Americans are often poor urban residential areas (Downey 2006). Population density (in people per square kilometer) is included as a control variable; created by multiplying the land area in meters by 0.001 and then dividing that value from the total population of the tract.

Socioeconomic status is operationalized through two independent variables; in order to account for both wealth and income (two mutually exclusive concepts). As per Smith's (2009) study, median housing value is used a proxy indicator of wealth. Two non-event cases were missing this value and were listwise excluded from the analyses. For the income variable, Smith's (2009) economic deprivation index is used. ${ }^{10}$ By combining seven variables that measure several nuanced aspects of poverty, the economic deprivation index provides a more valid representation of poverty than single

\footnotetext{
${ }^{10}$ The economic deprivation index used in this study is slightly different from Smith's. Due to the differences between 1990 and 2000 census questions, percent female headed households with no husband present and with own children under 18 and percent receiving public assistance income are used instead of percent female headed households and percent receiving welfare, respectively. Due to these differences, the index used in this study is expected to produce more conservative estimates of poverty than that of Smith's (2009) economic deprivation index. Also, Smith uses principle component factor analysis to correct for multicollinearity and to standardize the values in the index. Alternatively, the index employed in this paper uses variables standardized with the following re-code formula: variable value - mean/standard deviation (a negative sign was used on percent employed as a top executive and median income recodes in order to invert their values in order to match the direction of higher values meaning higher economic deprivation).
} 
variables (such as percent living below poverty line or mean income). This index ( $\alpha=$ .896) includes percent unemployed, percent living below the poverty line, percent receiving public assistance income, percent of female-headed households with no husband present and with own children under 18, percent without a high school diploma, percent employed as a top executive, and median income. Percent without a high school diploma was created by combining the percent of the population 25 years and older with less than $9^{\text {th }}$ grade with percent of the population 25 years and older with some high school but no diploma or GED. Percent employed as a top executive was computed by adding the number of males and females employed as a top executive, dividing that number by the business population for the tract, and then multiplied by 100 . The mean of 0.0 was imputed for two cases (including an event tract) which were missing all three values used to create this variable in order to construct their economic deprivation index score.

\section{Data Analysis}

The cross-sectional quantitative data derived from census and CERCLIS sources is used to study the dependent variable, presence of a Superfund site, as it relates to the following independent variables: percent African American (and percent African American squared), percent Hispanic, percent Asian, population density, median housing value, and economic deprivation. A quantitative design which employs logistic regression is utilized to determine any association between the given variables. As Baden et al. (2007) notes, "the logit model offers a straightforward estimation procedure consistent 
with the previous [environmental inequality] literature" (p. 176). Independent t-tests are also initially used to determine any bivariate relationships.

\section{Qualitative}

\section{Methodological Approach}

In an attempt to remedy the limitations of quantitative analyses and to better our understanding of the processes behind environmental inequalities, more research needs to incorporate qualitative methods into their design (Pellow 2000; Pulido et al. 1996). This study serves to research the phenomenon from a new perspective - one which uses the quantitative findings as a starting point, followed by deeper qualitative analysis which adds contextual meaning to these statistical findings - and adapts Pellow's (2007) approach to do so. In order to explore the structural and local forces that have contributed to environmental inequalities in Portland, a modified version of Pellow's (2007) methodological approach is employed. In an attempt to unpack the environmental inequalities associated with the contemporary transnational waste trade system, Pellow employs a methodological approach with four components: 1) a literature review of the history, previous research on the topic, and relevant theory, 2) a content analysis of government documents, NGO reports, and other sources, 3) semi-structured interviews with several of the world's leading environmental justice activists, and 4) active participation in environmental justice conferences (which also provides access to additional documents and reports).

Pellow (2007) notes that this methodological approach fits into the "critical advocacy research" framework. By working with environmental justice activists (both in 
interviews and at conferences), studies that use this format are able to objectively research environmental inequalities and simultaneously participate in social change efforts. Pellow contends that academics have an obligation to not only research social inequalities, but to be active participants in social change movements; because researching without participatory action is akin to "just fiddling while the world burns" (Pellow 2007:35).

This study adapts Pellow's (2007) methodological approach. Namely, a literature review of the historical forces which have shaped Portland's status quo environmental inequalities is complimented with semi-structured in-depth interviews with four of Portland's prominent environmental justice advocates and organizers. Furthermore, access to the sample was obtained by participating in local environmental justice conferences and events. These experiences also shaped the research design as they informed the researcher of current environmental justice conflicts that warranted further investigation. As modest is it may be, this research effort is guided by the critical advocacy research paradigm and (by conversing with and sharing the finished manuscript with the environmental justice activists who participated in the study) aims to contribute to Portland's environmental justice movement by increasing local understanding of environmental inequality processes.

Pellow's (2007) methodological approach (and the one used in the current study) is guided by the EIF theoretical framework as part of a larger effort to frame environmental inequality as a process and uncover the historical forces that have shaped and maintained the inequalities in question. Thus, the methodological approach and the 
EIF theory are speaking to one another and operate in synch. Utilizing the EIF framework, this research is centrally concerned with unearthing the stakeholders, history, and process of environmental inequality in Portland. Given this theoretical approach, interviews (and the historical analysis presented in the literature review) are an ideal means by which to gather valuable and esoteric information surrounding the forces and actors behind Portland's environmental inequalities (Pellow 2007; 2000). Although ethnographic methods may be appropriate for studies on individual environmental justice struggles (Pellow 2000), interviews with activists are more intuitive and useful in this context considering the broad scope of the research which examines Portland's numerous and often interlinking environmental inequalities (Pellow 2007). Lambert et al. (2006) conclude that interviews which cultivate local knowledge and insight into environmental inequality are the preferred method to compliment quantitative analyses. Thus, interviews are a good method for gathering qualitative data on the subject and offer contextual meaning to the quantitative results.

\section{Sample}

Much qualitative environmental inequality work relies on interview or ethnographic data collected directly from members of specific environmental justice communities (Pellow 2002; Pellow 2000; Pulido et al. 1996). In his (2007) book Resisting Global Toxics, Pellow introduces a new methodology for environmental justice research which relies on interview data from leading environmental justice advocates. This research borrows from this methodological approach. Thus, instead of gathering data directly from individuals that live or work in environmentally hazardous 
communities, this study utilizes interviews with key "expert" informants on Portland's environmental justice struggles. The phrase expert is used to distinguish the sample consisting of an environmental justice legal scholar, a county health department official, and two environmental justice community organizers - from the individuals who actually live in environmental justice communities.

Despite their expert status, it is theoretically possible that participants could live in environmental justice communities themselves. However, the interviewees did not express that this was the case and only spoke about the experiences of others suffering from environmental inequalities. All of the interviewees directly work with environmental justice communities, thus offering a great deal of firsthand knowledge and experiences with environmental injustices in the Portland area. However, only one participant has an office located in a known environmental justice community- and it is unclear whether he actually lives in that particular community or not. Regardless of their work in environmental justice communities, it seems that none of the participants routinely experience hazard exposure- the hallmark of experiencing environmental inequality.

All of the participants stressed the importance of giving environmental justice communities a voice and empowering them to be their own agents of change; thereby acknowledging the limitations of their ability to speak for others. Similarly, respondents suggested the research would be greatly benefited if it were to include interviews with some of those who actually live in environmental justice communities and experience toxin exposure on a daily basis. Despite their lack of personal toxin exposure, participants 
shared their unique personal backgrounds which inspired them to pursue environmental justice work in their career paths. Three of the four interviewees were from cultural communities commonly afflicted by inequitable hazard exposure, and consequently chose to devote their lives to the environmental justice cause in an attempt to contribute something positive to their specific cultural community (and to other similarly marginalized groups). The fourth participant - a white male with an environmental law background - explained that he started working in the area of environmental justice law and community organizing (around environmental justice) during his days in law school and has been dedicated to the line of work ever since. Although they come from varied cultural backgrounds, all respondents demonstrated intense passion for their work and expressed a great desire to help communities in need.

The sampling of "experts" was chosen for several reasons. Firstly, environmental justice activists are able to speak to environmental inequalities outside of sole personal experience, offering insider knowledge on the vast spectrum of Portland's environmental inequalities. Thus, instead of only speaking to a single struggle, this sampling approach cultivates a breadth of data on a variety of issues. Consequently, this enables exploration of the gamut of interlinking environmental inequalities present in the Portland area. Secondly, considering the research aims of exploring the structural and local forces which have shaped environmental inequality, experts offer critical insight into these complex processes which may be overlooked by lay persons who live in environmental justice communities. Considering that all participants work in the field of environmental justice (in one capacity or another), they are able to articulate the systemic and less 
obvious causes of environmental justice struggles in the area; which proves to be particularly useful when framing environmental inequalities from a multistakeholder reality (Pellow 2000).

The expert label is even more accurate when one considers the background of the participants. While they were diverse along racial and gender lines (one Latino male, one African American male, one African American woman, one white man), they were all middle class, middle aged, and highly educated; three of the participants had a legal degree and the other had a Master's in Public Health. All four participants were chosen due to their close connection to environmental justice struggles in Portland, representing a diverse class of stakeholders that have unique and varied interests in the struggles. Due to time constraints associated with a master's research project, the sample is relatively small. Still, it is an appropriate number as it allows for the collection of a significant amount of deep and detailed information from a variety of sources. By the fourth interview it was clear that several themes and environmental justice stories were reoccurring in each interview and that sufficient saturation was present.

It is important to note that this sample is not representative of all of the experiences, opinions, and knowledge regarding environmental inequalities in Portland, Oregon. Considering that this thesis lacks qualitative data from those who experience inequity on the "ground level," the data is inherently unrepresentative of lived environmental inequality experiences. Furthermore, the sample of experts included in the study lacks representativeness of "expert" knowledge as well. However, like many qualitative studies, representativeness is not an aim of this research. Furthermore, it is 
arguable that representativeness is intrinsically impossible for this kind of study and the type of data collected; it is unreasonable to assume that one could collect enough interview data from enough experts to achieve true representativeness. Despite this limitation, the data collected from the sample nevertheless offers rich insight into the stories behind environmental inequalities in Portland and allows for extensive investigation into the relevant history, processes, and stakeholders.

\section{Data Collection}

Face-to-face interviews were conducted either at Portland State University or at the participant's office. One of the interviews was done over the phone, but following the same method and script used in the face-to-face interviews. Interviews ranged from 35 to 55 minutes and were recorded with a digital audio recorder. In order to gather candid responses, participants signed a form of consent which guaranteed confidentiality and deidentification in this publication. An interview guide (see Appendix A) structured and focused the interviews, but left room for unpredicted discussions in order to ensure interpretive validity of the qualitative findings (Johnson 1997).The questions were open ended, which elicited long, passionate, and detailed responses from the participants. Interviews were designed to gather information about environmental inequality in Portland on the following subjects: current struggles, the history and processes behind them, and the multiple stakeholders involved. See Appendix A for the explicit questions asked. 
Analysis

In order to analyze the qualitative data, a modified general inductive approach is employed. Thomas (2006) notes that the general inductive analysis approach has three aims: 1) to compress extensive and wide-ranging raw text into a succinct summary format, 2) to find apparent links between the research aims and the summary findings, and 3) to build a theory or model about the fundamental structure of the processes or experiences that are apparent in the data. The modified general inductive process is explained in the following paragraphs.

First, the audio files were transcribed into a textual format. To amplify understanding of the data, each transcript was read two or three times before any actual analysis was attempted. Analysis was guided by Pellow's (2000) EIF framework, with particular emphasis placed on history/process and stakeholders. Analyzing Portland's environmental inequality history, processes, and stakeholders enables the researcher to answer the third research question (What structural and local forces contribute to environmental inequality in Portland?). After extensively reviewing the transcripts, it became clear that several environmental justice struggles (some unique, others overlapping) and multiple "structural and local forces" were reflected in the data. To consolidate this data and to link data across specific themes, a modified coding scheme was created (Thomas 2006). During the coding process, category labels and descriptions were given to specific segments of text. Links were then established between categories that had shared relationships. Memos were written about code categories to help organize the construction of the code tree (Thomas 2006). Tallying of codes helps assess 
frequency and prevalence of themes, but this was not possible with such a small sample size, so tallying was not employed in analysis. The modified coding process allowed major themes to emerge and helped link data from various interviews into a cohesive story.

The qualitative findings section is in a format reminiscent of a narrative, as it uses responses from all participants to form a comprehensive story on environmental inequalities and the local and structural forces behind them. Thus, extensive accounts of environmental inequalities are explored in the findings section and are couched within the EIF framework. After the specific environmental justice issue is described (who is most effected and by what hazard), the history, process, and stakeholders involved are explored in order to unpack the structural and local forces which have shaped the phenomenon. Collectively, these various environmental injustices help us understand the state of environmental inequalities in Portland and the interlinking forces which maintain them. 


\section{Findings}

\section{Quantitative Findings}

Univariate analysis of the data (see Table 1 below) reveals that very few tracts in Portland have Superfund sites present; only $5.8 \%$ of tracts in the metropolitan area contain one or more Superfund sites. On average, minority populations make up only a small percent of the racial makeup in Portland metro tracts. Whites on average make up more than $80 \%$ of a given census tract. Hispanics have the highest average percent of a tract population ( $\mathrm{x} \square=7.6$ ), with African Americans having the lowest ( $\mathrm{x} \square=4.2$ ).

\begin{tabular}{|c|c|c|}
\hline IVs & $\%$ & $\$$ \\
\hline Superfund site present $\mathrm{t}^{\mathrm{a}}$ & 5.8 & \\
\hline$\%$ African American & 4.2 & \\
\hline$\%$ Asian & 5.4 & \\
\hline$\%$ Hispanic & 7.6 & \\
\hline Median housing value & & 190,545 \\
\hline $\mathrm{N}$ (census tracts) & 311 & \\
\hline
\end{tabular}

With the exception of population density $(\mathrm{p}<.001)$, bivariate analyses (independent t-tests) exhibit no significant relationships between the dependent variable and any of the independent variables. However, subsequent multivariate analysis finds various significant associations once multiple variables are controlled for. As the following regression models will show, population density continues to exhibit the 
strongest relationship with the dependent variable; tracts with Superfund sites have significantly less-dense populations than tracts without them.

Table 2 (see page 62) exhibits multiple logistic regression models predicting Superfund site presence. Starting with Model 2 (Model 1 and 4 are discussed in the following paragraphs), the association between minority tract composition and Superfund site presence is assessed. Percent Hispanic proves to be an insignificant predictor of Superfund site presence. Conversely, percent African American ( $\mathrm{p}<.01)$, percent African American squared $(\mathrm{p}<.05)$, and percent Asian $(\mathrm{p}<.05)$ are all initially significant predictors for the presence of a Superfund site. While percent African American/percent African American squared exhibits a curvilinear relationship with Superfund site presence, percent Asian exhibits a negative relationship with the dependent variable. Contradicting the Asian component of the second hypothesis, for every one-percent increase in percent Asian, a tract is .817 times as likely to contain a Superfund site. However, the literature indicates that population density is a critical control variable, as the tracts which typically house Superfund sites (and other industrial facilities) are often sparsely populated when compared to other tracts in the city.

Accordingly, population density is controlled for in Model 3. This new model fits the data significantly better, as the Nagelkerke R-square increases from .113 to .324 after the addition of population density. Thus, the regression of these independent variables explains $32.4 \%$ of the variation in the dependent variable. The resulting analysis reveals population density $(\operatorname{Exp}(\mathrm{B})=.17, \mathrm{p}<.001)$ to be a confounding variable in the data, as percent Asian subsequently loses significance after inclusion of the control; population 
density is confounding the relationship between likelihood of a census tract containing a Superfund site and percent Asian. Thus, Model 3 answers the Asian component of the second research question (ultimately accepting the null); there is no significant association between percent Asian and the likelihood of a census tract containing a Superfund site. The association between percent African American, percent African American squared, and the dependent variable is further assessed in the following paragraphs.

Table 2. Logistic Regression Models Predicting Superfund Site Presence

\begin{tabular}{|c|c|c|c|c|}
\hline Variable & Model 1 & Model 2 & Model 3 & Model 4 \\
\hline \multicolumn{5}{|l|}{ Demographic Variables } \\
\hline \multirow[t]{2}{*}{$\%$ African American } & & $.473 * *$ & $.975^{* * *}$ & $.887 * *$ \\
\hline & & $(1.606)$ & $(2.65)$ & $(2.428)$ \\
\hline \multirow[t]{2}{*}{$\%$ African American ${ }^{2}$} & & $-.022 *$ & $-.047 * *$ & $-.044^{*}$ \\
\hline & & $(.979)$ & $(.954)$ & $(.957)$ \\
\hline \multirow[t]{2}{*}{$\%$ Asian } & & $-.202 *$ & -.068 & -.065 \\
\hline & & $(.817)$ & $(.935)$ & $(.937)$ \\
\hline \multirow[t]{2}{*}{$\%$ Hispanic } & & -.02 & -.01 & -.043 \\
\hline & & $(.981)$ & $(.99)$ & $(.958)$ \\
\hline \multicolumn{5}{|l|}{ Control Variable } \\
\hline \multirow[t]{2}{*}{ Population density } & $-1.317 * * *$ & & $-1.77 * * *$ & $-1.847 * * *$ \\
\hline & $(.268)$ & & $(.17)$ & $(.158)$ \\
\hline \multicolumn{5}{|l|}{ Socioeconomic Status } \\
\hline \multirow[t]{2}{*}{ Economic deprivation index } & $.108 *$ & & & .038 \\
\hline & $(1.114)$ & & & (1.039) \\
\hline \multirow[t]{2}{*}{ Median housing value } & & & & .0 \\
\hline & & & & $(1.0)$ \\
\hline Constant & -1.175 & -2.546 & -1.92 & -.220 \\
\hline Model chi-square & $21.708 * * *$ & $12.767 *$ & $38.241 * * *$ & $39.765 * * *$ \\
\hline Nagelkerke R-square & .189 & .113 & .324 & .336 \\
\hline $\mathrm{N}$ & 311 & 311 & 311 & 311 \\
\hline
\end{tabular}

Note: Unstandardized logistic coefficients with odds ratios in parentheses.

$* \mathrm{p}<.05 * * \mathrm{p}<.01 * * * \mathrm{p} \leq .001$

Source: U.S. Census (2000) and CERCLIS (2011).

Returning to Model 1, this logit model assesses the relationship between economic deprivation and the likelihood that a tract has a Superfund site, after controlling for population density. Both population density $(\operatorname{Exp}(B)=.268, \mathrm{p}<.001)$ and economic 
deprivation $(\operatorname{Exp}(B)=1.114, p<.05)$ are significant predictors for Superfund site presence. For every one unit increase in the economic deprivation index a tract is 1.114 times more likely to contain a Superfund site. Population density demonstrates an inverted trend; an incremental increase in population density in a census tract decreases the odds of Superfund site presence by .268 . However, after adjusting for race in Model 4, economic deprivation is no longer a significant predictor. In Model 4, only percent African American ( $\mathrm{p}<.01)$, percent African American squared $(\mathrm{p}<.05)$, and population density $(\mathrm{p}<.001)$ are significant. Population density exhibits an odds ratio of .158 in Model 4; for every incremental increase in a tract's population density, there is a predicted .158 decrease in likelihood of Superfund site presence. Model 4 nearly doubles the Nagelkerke R-square to .336 (when compared to Model 1), establishing a superior fit for the data.

Similar to Downey's (2006) findings on average toxic emissions, percent African American exhibits a curvilinear relationship with Superfund site presence. The inclusion of the percent African American squared term accounts for this varied relationship. However, the interpretation of the odds ratios is less intuitive as the slope is not constant. For a more useful statistic, SPSS was used to find the predicted probabilities of Superfund site presence by percent African American. This statistical evaluation offers an inflection point (the point in which the relationship between the dependent variable and percent African American becomes negative) and the associated peak probability of Superfund site presence for percent African American. The predicted probabilities of Superfund site presence by percent African American were assessed for Models 2 (race 
only) and 4 (all variables), with mean values inputted for all other independent variables in the respective models.

The resulting analyses reveal a curvilinear relationship between percent African American and the dependent variable. As tracts increase in percent African American so does their probability of containing a Superfund site. However, at $10.75 \%$ African American in Model 2 and 10.8\% in Model 4 (the inflection points) this relationship becomes negative. The only significant difference between Models 2 and 4 is that the maximum probability for Superfund site presence by percent African American is almost three times as high after population density and socioeconomic status are accounted for. Model 2, which only includes racial demographic variables in the model, has a peak probability of approximately .225 . The greatest probability of Superfund site presence skyrockets to approximately .60 in Model 4 after all the independent variables are included in the logit. The dramatic increase of peak probability in Model 4 demonstrates the strength of population density as a significant predictor of Superfund site presence and suggests that high levels of population density insulate census tracts from housing Superfund sites.

\section{Qualitative Findings}

The following section of this chapter details the qualitative findings of the research. The analysis of the qualitative data reveals that environmental inequalities are prevalent in the Portland metro. Participants spoke about a variety of environmental justice struggles that currently or previously defined the greater Portland area. Some of the environmental inequalities present in the qualitative data include: sustainability 
policies and other "greening" efforts neglect issues of equity, unsafe and segregated housing, exposure to chemicals in the home and workplace, subsistence fishing in toxic bodies of water, lead poisoning, asthma, air toxins, Superfund sites, and brownfields. Furthermore, respondents noted that minority and low-income residents are disproportionately burdened by these specific environmental hazards. As shown in the final section of this chapter, many of these environmental hazards are interlinked and work together to reinforce environmental health disparities. The themes that prove to be most important were touched on by the majority or all participants and consequently receive the bulk of attention in this section.

The qualitative findings presented in this chapter are guided by Pellow's (2000) EIF framework. These findings offer extensive insight into the history, process, and stakeholders of some of Portland's more prominent environmental inequality issues. Throughout the interviews, three specific environmental justice stories were prominent: selective sustainability, the Brownfield Showcase, and cumulative exposures. Not only are these examples of environmental inequality in and of themselves, but the three stories collectively serve to expose and explain some of the structural and local forces which have contributed to environmental inequalities in Portland. The remainder of this chapter offers a rigorous exploration of these three environmental inequality struggles.

\section{Selective Sustainability}

Portland is publically known as one of the "greenest" - or most environmentally conscious (both in advocacy and in practice) - places in the United States (Shandas and Messer 2008). However, some respondents explained that this paints a misleading picture 
of the city and that it undermines some dramatic disparities at hand. While many communities have the most up-to-date green technology available, farmer's markets, and other "green amenities," other areas are filled with toxic dilapidated houses, liquor stores, fast food restaurants, and subsequently lack much safe and accessible green space. Interviewees explained that the greenest neighborhoods are middle to upper class and predominantly white, while the communities that lack green amenities are predominately non-white and impoverished. "Participant 2", a community organizer, explains:

When we look at national funders we're talking about environmental justice, they're like: "what? Portland?" You look at Portland and you've got bike lanes everyway and green trees and grass and flowers and all that crap all over the place. Yet when you look closely and look at the racial divide in terms of exposures and outcomes, it's a drastic realization that despite all of those other positive things there's very specific communities that aren't benefiting from that. And it almost highlights it even more.

Specifically, sustainability policies and the distribution of green technologies in Portland have been markedly inequitable. This in and of itself is an explicit example of one of Pellow's (2002) indicators of environmental inequality. Pellow argues that "[t]he neglect of human health and social justice issues by the established environmental movement" constitutes environmental inequality, as does "[t]he exclusion of the poor and people of color from environmental decision making" (Pellow 2002:9). Multiple respondents spoke to both of these instances of environmental inequality and offered insight into the local processes which have dictated these outcomes. 
One of the community organizers interviewed - Participant 4 - works primarily with the Cully neighborhood; one of Portland's poorest and most diverse neighborhoods. During the interview the participant spoke in great depth about the disparities that the impoverished minority community faced. Participant 4 paints a drab picture of Cully, a neighborhood plagued with a plethora of environmental health issues:

Cully is one of the most, if not the most, park and habitat deficient neighborhoods in the city. It has concentrated poverty, concentrated numbers of people of color. Per the 2010 census... it has the most diverse census tract in the entire state...I think upwards of $75 \%$ (of the respondents anyway) reported being food insecure, using food stamps. And then if you look at two of the schools here in the neighborhood- Scott School... and then Rigler School... upwards of $85 \%$ of the students in those schools are on free or reduced lunch.

Illustrating a textbook case of environmental inequality, Participant 4 explains that Cully is concentrated with the poor, people of color, and disparate environmental hazards. In addition to the more obvious environmental inequalities present (lack of greenspace, unsafe and segregated housing), the interviewee also suggests that Portland's sustainability efforts are an explicit example of environmental inequality in Cully; arguing that research and implementation of green technology has been patently inequitable and only benefits traditionally privileged social groups and neighborhoods. In the following passage, Participant 4 explains how Cully's environmental inequalities are a direct consequence of sustainability efforts:

Clean air, clean water, uncontaminated land, environmental technologies (swales, district heating and cooling, eco-roofs); [these are] the kind of investments that Portland makes in certain 
neighborhoods and not in low-income neighborhoods. I believe that South Waterfront has two or three district heating and cooling feasibility studies. While a neighborhood like Cully, Lents, what have you has none. Even though you could make a strong case that those communities really need access to reliable and affordable energy, but no one has tried to figure out how to do that.

As the quote illustrates, Portland's sustainability efforts are an ironic case of environmental inequality as they signify an inequitable distribution of environmental goods and bads. Respondents explained that the neighborhoods that get the most greening efforts - such as the aforementioned South Waterfront or downtown Portland's Pearl District - are whiter, wealthier, and generally more environmentally sound in the first place than areas that fail to receive such remediation. The unequal distribution of sustainability technology and associated environmental quality is best described by a term I call "selective sustainability." By neglecting to include equity principles in its ideological framework and actual implementation, this process of selective sustainability enforces dramatic disparities in the Portland metropolitan area. In the following discussion, Participant 4 criticizes the lack of an equity focus in Portland's sustainability work:

Most of sustainability work focuses on environmental and financial performance and not on social or equity performance. I don't think that most sustainability practitioners in the public or private or foundation world wake up every day with an "equity to do list." So I think that at least in terms of the current allocation of resources under the rubric of sustainability, that's where that comes from. It's not something they think about, it's not something they put resources toward realizing. 
The respondent goes on to explain that a purposeful equity lens is needed for "true sustainability." As the poor and people of color are "not benefited as part of the routine operation of society," Participant 4 argues that affirmative efforts are needed to change inequality. Thus, sustainability work must actively attempt to bring its benefits to marginalized communities or the underserved will continue to be cast to the wayside. This sentiment is echoed by participants' criticism of the double bottom line business model; a model that attempts to make business endeavors both financially and environmentally sound. While the double bottom line approach is undoubtedly better for environmental and human health than models that only value financial performance, it neglects the fundamental issue of "social sustainability." ${ }^{11}$ Multiple participants interviewed erred in favor of triple bottom line models; business models which equally emphasize financial, environmental, and social equity priorities. Participants reasoned that triple bottom line models must be incorporated into local sustainability work in order to achieve true sustainability; a model of sustainability which includes environmental, financial, and social factors.

Participant 4 believes that triple bottom line models actually give community organizations (such as environmental justice organizations, minority advocacy groups, or neighborhood associations) a competitive advantage when seeking funding sources for sustainability work for their communities. In the following quote, Participant 4 explains how community groups can use [the triple bottom line's] equity principles as an effective leverage for securing resources from progressively minded funders:

\footnotetext{
${ }^{11}$ In addition to the environmental and economic realms, sustainability must have a social component which seeks to generate and sustain social health and well-being (Dillard et al. 2009).
} 
There are some [new] resources out there... searching for opportunities to achieve triple bottom line investments. They really want to see equity. Even if they don't know how to do it, and even if they're not the most inclusive organizations in the world, they really want to figure out how to do it. And this puts community groups in a fairly interesting competitive position I think.

Despite the recent uptick in equity minded investors, Participant 4 suggests that they are considerably fewer in number in Portland when compared to double bottom line institutions. This general lack of equity in sustainability work is even more insidious when one looks deeper into the historical processes behind it. Using a particular example as a case study of sorts, one participant explains how innovations in sustainability are enabled by government subsidies which favor established and traditionally white sustainability practitioners, perpetuating "selective sustainability." The City of Portland's Bureau of Planning and Sustainability routinely uses grant programs to help develop and implement sustainability technology and systems within the city. One particular grant, the Green Investment Fund (or GIF), "was meant to incent innovations in green building." However, the Bureau failed to include any equity requirements into the funded work that was being done. Participant 4 explains:

At least for the first several years of that program they didn't have to talk about equity. They didn't have to talk about their project team. They didn't have to talk about the beneficiaries of their project. They didn't have to talk about who they were subcontracting to, who they were going to hire; any of that kind of stuff.

Mirroring larger trends of privilege, almost every aspect of this work (both in the process and the result) benefited traditionally privileged groups. The engineers who 
designed the technology, the contractors that installed it, and the neighborhoods that received it were all largely white and well-to-do. The participant explains that this disparity only widens as the years pass; since innovations are subsidized on the front end, the groups initially involved are able to monopolize the market. Minority owned businesses that were not awarded GIF grants are now unable to compete against the established practitioners who jumped on in the beginning. Not only are the original funded groups already connected to the system, but they have the experience and the government subsidized research and development needed to do this kind of innovative work. This process effectively prohibits new, equity focused groups (or even minority owned contractors) from doing sustainability work in Portland. Instead, the benefits of sustainability in Portland continue to be reaped by traditionally privileged groups while marginalized communities bear the bulk of the city's environmental burdens.

As previously noted, sustainability practitioners are key stakeholders in this unique environmental inequality story. Not only do they neglect equity concerns in their work, but their work operates in a political/economic system that largely benefits a predominantly white and economically prosperous population. One participant argues that those who work in the sustainability sector have something to gain - notably income - and that their motives for protecting the environment are guided by a profit driven framework. In the following quote, Participant 4 outlines this "environmental professional class:"

I think that the traditional model of sustainability in Portland predominantly serves...the needs of an environmental professional class: developers, designers, architects, landscape architects, 
engineers, certain segments of the environmental

intelligentsia, certain environmental groups, certain

environmental agencies.

As the quote demonstrates, there are a variety of groups with competing and overlapping interests in this story. And like many environmental justice struggles, both monetary and environmental resources are at stake. While Portland's marginalized communities are in desperate need of social and environmental goods, traditionally privileged groups and areas continue to benefit from sustainability work. This disparity is magnified when one considers the interests of the environmental professional class; a largely white group whose socioeconomic livelihood is tied into sustainability work. It is within this complex struggle for monetary and environmental resources that this particular case of environmental inequality has emerged. Not only is the case of selective sustainability an instance of environmental inequality in and of itself, but it is one of the forces which have shaped other environmental inequalities in Portland, particularly in regard to unsafe and segregated housing. Selective sustainability is one of the primary reasons as to why some of Portland's whiter and more affluent neighborhoods are green utopias while marginalized communities continue to be characterized by environmental hazards and other unsustainable features.

Looking to the EIF theory, the case of selective sustainability demonstrates how Portland's environmental inequalities are a manifestation of the struggle for society's various valued resources between multiple stakeholders, and when the benefits and burdens of these resources are distributed unevenly (Pellow 2000). Commonly, these resources take the forms of power, wealth, status, and the ability to live and work in areas 
with high levels of environmental quality. EIF also informs us that those with higher levels of power, wealth, and prestige are more likely to: 1) live and work in areas with high levels of environmental quality, and 2) deprive stakeholders with less power, wealth, and prestige from accessing said resources (Pellow 2000).

Accordingly, there are some significant power forces at play within the context of selective sustainability. Those with high levels of power, wealth, and prestige are the driving forces behind sustainability work in Portland (be it governmental bodies and their representatives or sustainability practitioners) and tend to deploy sustainability projects in areas in which they themselves are likely to work and live. According to EIF, these influential stakeholders are not simply playing favorites and purposefully benefitting fellow white middle/upper class Portlanders (even though that may be the case sometimes). Rather, the stakeholders on the receiving end (as compared to sustainability practitioners and the like) are able to use their power, wealth, and prestige to secure sustainability upgrades for their neighborhoods and workplaces. Simply put, those with more financial resources and social capital (an overwhelmingly white class in the Portland context) are able to use these means to garner sustainability technology for the areas in which they live and work. Essentially, powerful stakeholders who invest in sustainability systems are using their resources to enhance their own environmental quality; they are not intentionally marginalizing the poor and people of color.

Even though it is not a zero-sum game, this process of selective sustainability creates dramatic disparities in environmental goods between Portland's various neighborhoods. Accordingly, sustainability technology is concentrated in affluent white 
areas and is virtually nonexistent in impoverished communities of color. The neighborhoods that are lacking in power, wealth, and prestige are simply unable to effectively marshal the resources needed to implement sustainability programs in their community. Thus, Portland's prestigious, wealthy, and/or powerful citizens - an overwhelmingly white group - are the ones who continue to enjoy the majority of the benefits associated with the city's sustainability initiatives. In sum, EIF provides a powerful explanatory tool for this particular environmental justice struggle and demonstrates that the inequalities associated with selective sustainability are a result of various stakeholders' competition for (and unequal access to) the resources outlined above (Pellow 2000).

\section{Brownfield Showcase}

Similar to the case of selective sustainability, a second example of inequitable development was a common thread in the interviews. Many of the informants interviewed spoke about the EPA's Brownfield Showcase Award that was supposed to clean up several brownfield sites in North and Northeast Portland. Three out of four interviewees mentioned that they were extensively and personally involved in this particular environmental justice struggle. Throughout the interviews participants spoke in great depth about the history, process, and stakeholders of the Brownfield Showcase, enabling an extensive analysis of the formation of the environmental inequality.

Participant 1, an environmental justice lawyer and community organizer, describes his experience working on the Brownfield Showcase:

So 11 years ago I got involved with community efforts in North and Northeast Portland to work 
with the city of Portland to use EPA money - EPA had given an award called the Brownfield Showcase Award in 1998, to document, identify, assess and prioritize [Portland's brownfields that need to be cleaned up]- and that's kind of a magic language around process that we like to see in a community based effort. We want community folks to be engaged at every step of the way; including identification of the hazard or problem, the assessment of the problem, and then the prioritization of how to fix the problem and where to spend the resources.

However, the interviewee explains that this process did not go as smoothly as planned. After studying Portland's brownfields, it was clear that most of them were located in North/Northeast Portland- the very areas that the majority of Portland's lowincome and minority residents are concentrated in. Community members from these areas and organizers wanted to clean up the sites, but were posed with a considerable problem: how do they make these neighborhoods safer and cleaner without creating pressures of displacement? After a community cleans up its brownfield sites, the area becomes more attractive to families of means. Participant 1 reasons that gentrification and displacement are the "pernicious unintentional consequences of cleaning up areas." However, respondents explained that getting the community actively involved in the remediation process is a critical mechanism to prevent displacement. If the community is able to mobilize around the issue of cleanup and is empowered throughout this process, they are increasingly insulated against pressures of displacement. In the following quote, one participant explains how to circumvent gentrification problems which tend to follow cleanup efforts in hazardous areas: 
So how do we work against that? Well, a mobilized empowered community is less vulnerable to those kinds of pressures or forces. So if you can actually use the brownfield remediation process... as a hook for the community empowerment and the mobilization, you're actually providing this opportunity for community folks to empower themselves and protect themselves against the very forces that could otherwise drive them out or displace them.

In order to facilitate the process of community empowerment through brownfield remediation, organizers held community meetings with North/Northeast residents in order to collectively decide as a community which brownfields were the highest priority and should be selected for EPA funded remediation. Between fifteen to one hundred community members were present at these various meetings, all with diverse interests; many of which wanted their particular property to be one of the few chosen for remediation. Ultimately, the community was able to choose multiple sites in North/Northeast Portland that were to be cleaned up with the EPA Brownfield Showcase Award. Of particular concern were schools in North/Northeast Portland that were contaminated with lead. Unfortunately, these toxic public schools would never be cleaned.

Despite the promises of cleaning up the marginalized community, respondents explained that much of the funds never materialized. Instead of funding the cleanup of the proposed sites in North/Northeast Portland, participants explained that a large portion of the Showcase money was diverted into the redevelopment of the south waterfront. Nestled on the Portland Harbor (Portland's biggest Superfund site), the south waterfront was Portland's largest brownfield at the time. While the defunct industrial area was in 
dire need of remediation, the reallocation of funds away from poor communities of color and "into the pockets of Homer Williams and the developers" illustrates Portland's trend of environmental justice struggles that stem from inequitable development. Adding insult to injury, not only were promises broken to clean up environmental justice communities of North and Northeast Portland, but the south waterfront area was purposefully developed into an extremely affluent area which caters to a prosperous and overwhelmingly white population. Participant 1 explains how this process only exaggerated existing disparities:

And a lot of the [Showcase] money got redirected and got put into the pockets of Homer Williams and the developers to build those massive market-rate condo towers that are sitting at half or two-thirds filled right now because there isn't the demand for it. Whereas we missed out on an opportunity to actually deliver on the promises that we made to the community in North or Northeast Portland and then we also missed out on the affordable housing opportunity to build units in that community and make that an affordable community that could take advantage of that streetcar line that drops you off from the heart of the south waterfront community right into the heart of downtown.

This quote highlights the complexities in this particular environmental inequality story and exposes how stakeholders' interests dictated the outcome. One key stakeholder mentioned in the quote is Homer Williams. Homer Williams is the chairman of Williams and Dame Development (WDD), an extremely successful real estate development company that has been a tremendously influential figure in shaping Portland in recent decades. In addition to the luxury sky rises that were built on the remediated south waterfront, WDD were the developers behind the redevelopment of Portland's affluent 
Pearl District and other major projects in Portland. But how was WDD able to "win" a significant amount of the Showcase Award, considering the funds had already been promised to be used in North/Northeast Portland? Participant 4 reasons that the relative influence and prominence of WDD is directly related to their ability to divert previously allocated Showcase funds to finance their massive south waterfront project:

If I'm a policy maker, a decision maker, and I have these one folks [WDD] and they've got the resources to talk to me all the time and they've got lawyers and designers and money. And I have these other folks [N/NE community members and organizers] who I don't hear from very often, just life being what it is, I'm probably gonna eventually tip in the favor of the ones who get to talk to me all the time.

Just like the case of selective sustainability, a certain professional organization had financial interests in the redevelopment of a hazardous area. This particular environmental justice struggle was heavily influenced by those interests. Using the EIF framework, this data suggests that the environmental inequalities in question were a result of a conflict for scarce resources. In a struggle for environmental health equity, poor communities of color were fighting for brownfield remediation in their neighborhoods and schools (competing for environmental resources). Meanwhile, WDD saw the Brownfield Showcase as an opportunity for financial gain (competing for economic resources). It is the intersection of these "competitions," and surely several others that were not reflected in the data, that the Brownfield Showcase environmental inequalities emerged. 
Consistent with the selective sustainability example, local businesses (and their relationship to government) have dramatic impact on environmental justice issues in the Portland area. In this case, a prominent development firm was able to divert and acquire lucrative contracts from the EPA in order to remediate and rebuild the south waterfront area. However this came at a dramatic cost to traditionally marginalized communities, as the revitalization of the south waterfront meant that N/NE Portland would not receive much of the brownfield remediation it was promised. Illustrating an archetypal case of environmental inequality, North/Northeast Portland's comparative lack of social, political, and (most importantly) economic power was ultimately at the heart of their unexpected loss of brownfield remediation to WDD and the south waterfront.

\section{Cumulative Exposures}

The third and final case of environmental inequality in Portland that was overwhelmingly present in the data - "cumulative exposures" - is covered in the following pages. A unifying theme across all interviews was the notion of cumulative exposures; a massive set of concentrated and interlinked environmental inequalities that affect certain populations. Portland's minority and low-income residents are not faced with a single environmental hazard, varied by the neighborhood in which they live. Rather, Portland's environmental justice communities experience a spectrum of connected environmental inequalities, a concept dubbed "cumulative exposures" by one participant. The words of Participant 1 - an environmental justice community organizer appropriately summarizes the issue:

Our laws and regulations are very much geared towards single media, single sites, single bad actors 
- and it's not the way that communities experience exposure and pollution. They experience it cumulatively.

Informants explained that the cumulative exposure phenomenon starts with where one lives. Much of Portland's multifamily housing (apartment complexes, housing projects, and other compartmentalized residential buildings) serve as a "buffer zone" between the city's environmental hazards and more affluent residential communities. Participants explained that multifamily housing units, as compared to neighborhoods with single family homes, are concentrated sites of the impoverished, people of color, and toxins. According to the participants, multifamily units are often located near highways, freeways, and other major roadways, contributing to elevated levels of air toxins. Respondents argued that higher rates of asthma amongst Portland's African American community is linked to this inequitable distribution of roadways (Urban League of Portland 2009). In addition to roadways, multifamily housing areas in Portland are also more likely to be near light industrial and heavy commercial facilities. This could range from paint shops, manufacturing plants, or even laundry mats; all of which pose significant risk of contamination to nearby communities. As Participant 1 notes:

So these kind of industrial or heavy commercial activities will tend to concentrate themselves around areas where there's cheap, affordable housing. Or conversely, we build our affordable housing in areas where there is a concentration of pollution sources.

As suggested in the quote, unsafe and segregated housing is at the root of the issue of cumulative exposures. Certain communities in Portland are overburdened by a variety of environmental hazards; such as disproportionately high levels of air pollution 
(which corresponds with higher levels of asthma and concentrations of roadways), lead paint filled homes and schools, exposure to cheap and unsafe household chemicals, and concentrations of toxic industrial activity. Respondents were quick to note that these toxic neighborhoods did not just suffer from disproportionate pollution levels, but they are also greatly lacking access to greenspace, outdoor recreation opportunities, and healthy food. As Participant 1 concludes, "So when you combine the two you have a pretty overwhelming situation." And as all participants remarked, these areas are also the poorest and "brownest" parts of the metro. Respondents described a number of "sacrifice zones" in Portland that fit the bill for poor, polluted, communities of color. Interviewees cited North, Northeast (Albina, Cully), and outer Southeast (Lents, Rockwood) parts of the Portland metro as "those geographic areas that actually rose to the level of what we would describe as environmental justice communities" (Participant 2).

Returning to the classic environmental inequality "chicken or egg" question: which came first to Portland's sacrifice areas- environmental hazards or impoverished communities of color? Are industrial facilities, roadways, and other toxic sites built in recognized poor minority communities, or do these marginalized populations migrate to newly established toxic locales? Interviewees weighed in on this question and some of the other structural and local forces which have helped set the stage for the cumulative exposures phenomenon. Portland's history of segregation and displacement, free market forces, local jurisdictions and more were cited as root causes of the issue.

Before examining the chicken or egg phenomenon, it is important to stress Portland's history of segregation and displacement as a critical historical force that has 
shaped current environmental justice issues in the area. Multiple respondents referenced or explained in detail Portland's stark history of racial and economic inequality. Since this historical process has already been comprehensively examined in the literature review chapter, it is not necessary to mull over Portland's history a second time by extensively exploring the interview data on the subject. However, a brief summary is as follows. Respondents echoed the historical accounts present in the literature review and affirmed the impact of Vanport, Albina, segregation, red lining, urban renewal, gentrification, and displacement as core historical forces which have been immensely influential in the creation and maintenance of Portland's environmental health disparities, racialized income inequality, and sacrifice zones. As a result, Portland's low-income and nonwhite residents are clustered in certain parts of the city- neighborhoods which also happen to be the most toxic and greenspace deficient in the metro. These historical processes set the stage for status quo environmental inequalities, with segregation being a fundamental feature of this process.

Respondents spoke in depth about a variety of structural and local forces that create and maintain environmental inequalities in Portland. Returning to the issue of the chicken or the egg: when asked if hazardous sites are intentionally placed in poor minority communities (or conversely if these communities are subsequently formed within or contingent to hazardous areas), one respondent uses the term "coming to the nuisance" to describe the situation. The informant explains that it is both the chicken and the egg:

We talk about as "coming to the nuisance"...

Assuming there was residential housing around the 
industrial zoned area, the folks who have money or means move out. Those will tend to be white folks. And the folks who were left behind are generally poorer and browner. And the folks who move into those vacant housing units or new housing that's constructed around that industrial zoned area will tend to be poorer and browner than before. So the demographics of the community change after the industrial facility is sited, but industrial facilities are also sited disproportionately in areas that are poorer and browner. So they work collectively and both ways at the same time.

As suggested in the quote, respondents explained that one's socioeconomic status is intricately linked to their race. This concept proves to be a key feature of the chicken and the egg phenomenon. Multiple respondents suggest that the intersection of race and class is ultimately at the heart of Portland's environmental inequality problems, as various structural features of society inhibit affluence and socioeconomic mobility for racial minorities; contributing to their propensity to living in hazardous areas. Demonstrating their academic roots, participants spoke in depth about a variety of structural and local forces that have perpetuated the race-class connection; such as generational wealth disparities, historical racism, and institutional racism (and its effect on jobs, housing, the criminal justice system, and educational opportunities). True to the phrase "cumulative exposures," these insidious social inequalities overlap and reinforce each other. Similarly, so do the various environmental inequalities that fall under the cumulative exposures phenomenon, creating a snowball effect of sorts.

Adding mass to the cumulative exposures snowball, respondents weighed in on the free market's role on cumulative environmental inequalities. Multiple informants reason that free market dynamics, and the presence of institutionalized racism within 
them, are at the heart of cumulative environmental inequalities in Portland. Participant 1 argues that the free market is not as natural as it is made to seem. "In fact, the market is heavily regulated" he contends. Redlining, racial steering, individual discrimination, and other "practices that used to be legal but are now not, but persist in an institutional form in one way or another" limit geographic mobility for Portland's minority and low-income populations (Participant 1). Participants explained that when left with fewer housing options than privileged groups, masses of poor and minority families subsequently flood newly established toxic areas which offer cheap housing that seems to cater to minority and low-income populations. Alongside this process, toxic facilities are often sited in areas concentrated with marginalized populations. Disproportionate siting on the front end is thus complimented by a consequential influx of poor and nonwhite residents, ultimately exaggerating segregation and environmental health disparities.

Constituting one of the key stakeholders, local jurisdictions rely on free market forces for economic prosperity. However, this process (whether intentional or not) contributes to segregation and cumulative environmental inequalities. Specifically, local jurisdictions have a "perverse incentive" - as one participant put it - to actually foster gentrification and displacement. While national trends might reflect a similar story, Oregon is unique in this case as the state does not have a sales tax. Accordingly, local jurisdictions in the Portland area rely heavily on property taxes to fund city operations (which includes everything from funding the maintenance of city parks to paying city employees' salaries). 
In order to finance current city operations and to raise additional funds in order to accommodate new and increased needs, local jurisdictions often seek to raise property values. Participants explained that this is typically done through urban renewal projects which aim to remodel a less desirable area (often an impoverished community of color) into one that will attract new businesses, homeowners, and commerce. Not only does this bring in more tenants and thus more property tax revenue for the local jurisdiction, but the taxes collected are now considerably higher thanks to the increased property values that are a consequence of urban renewal projects. As previously noted, the target communities for urban renewal are often poor and concentrated with racial minorities. Despite the increase in living standards, the marginalized residents of these areas will likely not benefit from them. Instead of enjoying the new comforts (and potentially a safer environment), many of the longstanding residents of these communities are unable to afford the higher cost of living and are subsequently left with no choice other than moving to a cheaper part of the city.

Magnifying this problem, unscrupulous business persons have been known to offer homeowners in recently gentrified areas more than double what they originally paid for their home, without telling them that the property is actually worth at least twice that figure. Participant 1 explains:

So you have a lot of predatory buying and the net effect is renters and homeowners who were sucked into selling below market value have moved out and have been replaced largely by either speculators or ... white and affluent residents. 
Furthermore, the influx of new (and predominantly white) residents into the neighborhood changes the character of the community; friends and neighbors move away, the sights, sounds, and "feel" of the neighborhood change, and businesses no longer cater to the specific culture that once defined the area. For long standing minority residents, this makes their home suddenly less desirable (especially considering the increased cost of living). The pressures of displacement are so intense that some members of Portland's African American community prefer to call the city projects "urban removal." Participants noted that the Historic Mississippi District and the Alberta Arts District are two archetypes of this phenomenon.

As previously explained, these marginalized populations are restrained by forces which limit their geographic mobility. Participants spoke in depth about the consequences of limited geographic mobility. Specifically, displaced members of urban renewal communities are often only able to afford new homes that are located in areas with significantly higher levels of environmental hazards than more affluent parts of the city. Participants explained that the recent displacement trend has shifted low-income and minority residents to remote locales in the Southeasternmost parts of the city, which also happen to be the most environmentally hazardous. According to the respondents, Outer Southeast Portland is associated with a variety of environmental health disparities and public health problems. Concentrated with low-income and minority residents (partly a consequence of displacement trends), outer Southeast Portland has one of the city's lowest life expectancy rates, highest rates of mortality, and highest concentrations of air pollution. Furthermore, outer Southeast residents (especially those east of I-205) suffer 
from transportation problems; costs of transit are higher, travel times are longer, miles traveled are higher, and public transit options are weaker and are grossly inconvenient when compared to those who live in the city center.

Further exacerbating the problem of displacement, Portland is experiencing what one participant calls "the reverse of white flight." No longer are middle class white families fleeing the city for the suburbs. Instead, they are migrating from the suburban areas back to the urban core. The reverse white flight trend has had the consequence of freeing up old housing stock on the edges of the metro that has often been converted into "affordable" multifamily housing. Participant 1 explains:

Now we're seeing the reverse trend happen- where living in the city has all of a sudden become more desirable. Living in a more dense (sic) environment, living with access to amenities, to transportation, to jobs has made living in urban environments more attractive to white families of means. So you have folks leaving the suburbs leaving behind older housing stock that gets converted to multifamily, cheap housing.

In short, local jurisdictions are one of the primary forces behind cumulative exposures, particularly in regard to unsafe and segregated housing. Since there is no sales tax, local jurisdictions rely on property tax and often need to generate more property tax revenue in order to keep up with rising costs of running a city. Urban renewal has been one of the primary mechanisms to facilitate this process. Urban renewal projects create a variety of social and economic pressures for displacement of longstanding poor and minority residents. Due to forces which limit their geographic mobility, displaced families often move to poorer and more environmentally hazardous areas- notably outer 
Southeast Portland. The availability of low-income housing in this area is in part a consequence of reverse white flight that has freed up the old housing stock on the fringes of the city; housing which has in turn been remodeled into multifamily housing units. Due to all these processes, outer Southeast Portland - a community rife with environmental hazards - is increasingly concentrated with the poor and families of color.

As the local jurisdictions discussion shows, local government is one of the key stakeholders in this story. In addition to the urban renewal process, government is an implicated party in the cumulative exposures phenomenon in a variety of other ways as well. Despite their role in creating and perpetuating environmental inequalities, local government has taken a variety of steps to ameliorate environmental health disparities. Recently, the Multnomah County Health Department played a major role in banning baby sippy cups that contain the dangerous chemical BPA. Participant 2 works for the Multnomah County Health Department and directly worked on the ban. Reasoning that low-income and minority populations were at higher risk of using these toxic containers, Participant 2 explains that this act is part of a larger effort to incorporate an equity lens into local government programs.

As the preceding paragraphs demonstrate, local government has a long road ahead of them if they are to eliminate their role in environmental inequality formation. However, as Participant 2 explained, Portland's local government is starting to heed the call for addressing local economic and racial inequalities. Despite some limitations, Participant 2 describes the health department as one of the most "progressive" in the nation: 
I don't know if our cognizance, our recognition, of the issue [environmental inequalities] is any more sophisticated. But the dialogue, the rhetoric, and putting it out front I think is much more advanced than a lot of other health departments... And that's where I think its unique is that we have an active policy agenda that gets shaped and shifted through both environmental justice and health equity analysis.

Unfortunately, there are a variety of barriers that inhibit the local government's ability to address and solve environmental inequality issues. Multiple respondents reasoned that cumulative exposures are difficult for the government to tackle as they aren't a single source of hazard. Participant 2 gives an example:

When you have a stationary source where you can point and say "you know what, the chromium is coming right from there." You can point at it, regulate it, and mitigate it. It becomes a very clear strategy.

Informants explained that local policies that aim to curb environmental health disparities operate within this "single source framework," making cumulative exposures a problematic target for policy oriented solutions. Similarly, respondents explain that local government typically relies on regulating the procedural elements of an issue, instead of addressing the larger issue at hand: the distribution of benefits and burdens. For example, redlining is no longer a legal practice. Despite this procedural regulation, segregation still characterizes the greater Portland area. And as the qualitative findings have shown, segregated communities are on the losing side of the distribution of benefits and burdens. Participant 1 - an environmental justice attorney - explains how the regulation of procedurals is unable to address the unequal distribution of benefits and burdens: 
We delude ourselves into thinking that "Oh, well if the process is fair-that's what America's

about."...But it doesn't dictate the outcome...Procedural regulations that give communities the veneer of equal opportunity in the process lulls communities into the false sense of believing that they're truly being guaranteed equal protection. When in fact they're being given an opportunity that's not truly meaningful because they can't really influence the outcome. The distribution of the benefits and burdens doesn't change. The status quo doesn't change.

Local businesses and business alliances are also key stakeholders in cumulative exposures and represent another barrier that restricts local government's ability to reduce environmental inequalities. Respondents harped on the immense influence of business interests on policy initiatives and explained that powerful business alliances are often one of the biggest obstacles to pushing policies forward. Participant 2 - the health department official - explained that local government often has to reach out and receive permission from relevant business organizations before pursuing any legislation. Without the explicit buy-in from businesses that may be effected (and the business alliances and organizations that represent them), these business groups will undermine any legislative efforts. The health department official even admitted that his department would probably not have been able to ban BPA-laden sippy cups if the Portland Business Alliance had been opposed to the restriction.

The health department representative reasons that the current economic climate exacerbates this problem as anything that could affect jobs, profits, or commerce is demonized and greatly limits its political efficacy. Furthermore, local governments are economically limited and funding for new programs and regulations is scarce at best. It is 
the intersection of these two issues - business interests and limited governmental funds that turn legislative efforts into a "political quagmire." He explains that industries have such immense influence on the legislative process that they can retaliate against the departments that regulate them and cause them to lose funding. Not only could governmental departments lose vital funding for programs that help the underserved, but governmental employees' jobs could even be threatened if they were to pursue legislation deemed controversial by local business interests. As a result, local government is generally limited to "cost neutral" policies that have minimal to no effect on regional business prosperity. This limiting framework prevents local governments from achieving much significant change when attempting to curb environmental health disparities.

In conclusion, Portland's environmental justice communities are not faced with one hazard or toxin; rather they are plagued by a variety of connected health disparities. Thus, cumulative exposures constitute one of the largest environmental inequalities that span the Portland metro. At the heart of the cumulative exposures phenomenon is unsafe and segregated housing. Segregated and impoverished communities of color are afflicted with a gamut of environmental inequalities and lack much insulation from these disparities. Historical, governmental, business, and capitalist forces are linked to the formation of cumulative exposures and operate in unison to perpetuate cumulative environmental inequalities. True to Pellow's (2000) argument, the participants' explanations of Portland's cumulative exposures demonstrate that environmental inequalities are not a discrete set of events. Instead, they are a result of the complex interests of a myriad of stakeholders. As these various stakeholders (governmental 
organizations, businesses, neighborhoods, and more) compete for various scarce resources (clean and affordable living environments, land for industrial or commercial sites, and monetary resources), cumulative exposures are created and maintained. 


\section{Conclusion and Discussion}

This research aims to examine environmental inequality in Portland, and does so quantitatively by assessing the racial and economic differences in the populations who live near Superfund sites and by qualitatively exploring the structural and local forces that have contributed to the phenomenon. By combining the two methods the research is able to account for both the existence of spatial environmental inequality in Portland as well as the unique historical forces that contribute to these outcomes. This section shall assess the quantitative hypotheses, engage the methodological and race/income debates by comparing the quantitative results with previous studies on Portland, link the quantitative and the qualitative findings for a clearer picture of environmental inequalities in the area, discuss the limitations of the study, and will conclude with a discussion of the next steps for future research endeavors on the topic.

Race and socioeconomic status are often strong predictors of one's likelihood of living in a toxic environment (Bowen 2002). Previous research has shown that environmental inequality is problematic for Portland's poor (Smith 2009), African Americans, and Hispanics (Downey 2006). However, little is known about this process and what forces contribute to the formation of this phenomenon (Pellow 2000). Before exploring the processes behind it, the quantitative bearings on the research questions and hypotheses shall be assessed. The first hypothesis of this research addressed the effect of poverty on the likelihood of living near a Superfund site. Contradicting the first hypothesis and ultimately accepting the null, the quantitative findings ultimately suggest that one's wealth (approximated by median home value) and level of economic 
deprivation are not significantly associated with Superfund site presence. Even though economic deprivation is initially a significant predictor of the dependent variable, the relationship vanishes after racial demographic characteristics are accounted for in the subsequent logit model.

Conversely, once all variables are included in the logit model, the findings exhibit significant associations only with percent African American and percent African American squared (excluding the population density control). These findings partially confirm the second hypothesis, that racial minorities are disproportionately represented in Superfund site tracts. Specifically, African Americans prove to be overrepresented in tracts that house Superfund sites. This relationship proves to be a curvilinear one, as increases in percent African American are associated with an increase in probability of Superfund site presence until $10.8 \%$ African American (which signifies the peak probability of approximately $60 \%$ ), after which the relationship with the dependent variable becomes negative. To put this finding in context, consider the difference in the average percent African American of Portland's census tracts $(\mathrm{x} \square=4.2)$ and the inflection point of the predicted probabilities of Superfund site presence by percent African American (inflection point=10.8). Tracts with the highest probability of containing a Superfund site are over double the average percent African American for Portland's census tracts. The nonlinear relationship confirms Downey's (2006) contention that environmental hazards are concentrated in neighborhoods with high percentages of minorities, but not in areas with the highest concentrations of minorities (within a given 
region). Thus, the curvilinear relationship stems from the relatively minimal industrial activity in highly segregated, urban, poor, communities of color (Downey 2006).

Considering that race explains away the significance of economic deprivation, one can gather valuable insights from the interplay of these two variables. While economic deprivation is initially a significant predictor in Model 1, Model 4 suggests that percent African American and population density are the strongest predictors of Superfund site presence. Whereas percent African American demonstrates a curvilinear association with the dependent variable (a relationship captured by the inclusion of the percent African American squared variable), lower levels of population density are associated with higher likelihoods of Superfund site presence. Despite the fact that economic deprivation loses significance after including racial variables in the logit, the predicted probabilities suggest that socioeconomic status is still an important part of this story. Since the peak predicted probabilities of Superfund site presence by percent African American are nearly three-fold once socioeconomic status and population density are accounted for, it can be inferred that tracts with high levels of economic deprivation, low levels of population density, and populations that are approximately $11 \%$ African American are at highest risk of housing a Superfund site.

Furthermore, this particular finding allows this research to engage the "race vs. class" debate that characterizes the environmental inequality literature (Crowder and Downey 2010). As these results demonstrate, race and class do not exist isolated in a vacuum. Rather, they operate together and often work collectively as predictors of environmental inequality. These findings are also reaffirmed by qualitative results 
pertaining to the intersection of race and class- or more particularly the intersection of minority and poverty status. Consistent with previous literature (Williams and Collins 2001), respondents explained how race and class are connected via a variety of ways. The race-class connection appears in broad forms (geographic immobility, generational wealth disparities, historical racism, and institutional racism in the criminal justice and education systems) as well as more Portland specific forms (redlining in Albina, gentrification and displacement, and other inequitable housing phenomena unique to the Portland area). As these forces demonstrate, Portland's racial minorities have historically struggled with fewer life chances than that afforded to the overwhelmingly white population of the region. As educational, housing, career, wealth accumulation, and other opportunities are less frequent and of lower quality for much of Portland's minority population, a stark association between one's race and their socioeconomic status becomes readily apparent. Thus, the race vs. class debate is an arbitrary one, as the two statuses are intricately linked by a gamut of social forces.

In order to compare results and to create a design guided by previous literature, the quantitative design was purposefully constructed similar to Smith's (2009) study on Portland Superfund site environmental inequality in 1990. The following parts of the design are the same: tract level unit of analysis, analyses examine the three counties that comprise the Portland metro, economic deprivation index (with slight modifications due to differences in 1990 and 2000 census data), median housing value as a proxy for wealth, Superfund sites as an indicator of hazard, population density as a control, and logistic regression analysis. However, this design employs percent African American as 
the race variable (as well as additional percent Hispanic and percent Asian), while Smith uses a dissimimilarity index of black/white segregation. Percent African American et al. was chosen for two reasons: 1) in order for additional comparison with Downey's (2006) findings (which is discussed in a later part of this chapter), and 2) due to missing census data, the dissimilarity index is unable to be calculated for about 50 tracts, causing them to be excluded from the analysis. Considering the number of cases in the analysis is already relatively low $(\mathrm{N}=311)$, proper regression techniques could be greatly hindered by the loss of 50 census tracts.

Smith's study ultimately concludes that economic deprivation is the strongest predictor of Superfund site presence, with higher levels of economic deprivation being associated with a higher likelihood of Superfund site presence. However the models from the present study conclude the opposite; race, specifically percent African American, is the stronger predictor for presence of a Superfund site. Perhaps the use of percent African American etc. instead of the segregation index accounts for this discrepancy. Also, it is possible that the comparatively conservative estimates of poverty gleaned from the economic deprivation index used in this study contribute to its lack of significance (once racial variables are added to the logit). Or, maybe the salience of income has declined from 1990-2000 in relation to Superfund site proximity. The qualitative data lends support to this hypothesis. Multiple respondents stressed the importance of race in Portland environmental inequalities, noting that the African American community is arguably the most affected. Furthermore, Portland's urban renewal programs that displaced much of the African American population from certain segments of Albina had 
yet to begin in 1990. Conversely, these programs were in full swing by 2000 .

Accordingly, gentrification and significant displacement of African American residents was apparent by 1999 (Gibson 2007). As respondents explained, various forces inhibit geographical mobility for these displaced families and as a result they often move to cheaper and [consequently] more toxic areas; commonly to areas near industrial and heavy commercial activity. Thus, it is possible that the demographic makeup of census tracts which housed Superfund sites experienced a surge of new African American residents throughout the 90's following the urban renewal projects of that decade; explaining the difference in Smith's findings from those presented in this thesis. Returning to the second hypothesis (which pertains to race), the quantitative analyses elicit some interesting findings on the two other racial groups included in the study. The null hypothesis is accepted for the other two race variables included - percent Asian and percent Hispanic. While increases in percent Asian were initially significantly associated with decreased likelihood of Superfund site presence, the relationship vanishes after population density is controlled for. Therefore, population density proves to be a confounding variable in this relationship. Since Superfund sites are typically located in sparsely populated areas, population density is a critical control variable (Smith 2009). Thus, percent Asian does not seem to insulate a tract from Superfund sites. Rather, this confounding relationship suggests that Asians tend to live in lesser-densely populated tracts in Portland. To the researcher's knowledge, this is the first academic quantitative environmental inequality study on Portland to ever include Asians in the design. 
The lack of significance for percent Hispanic is an interesting finding, as it contradicts Downey's (2006) study which finds a significant association with percent Hispanic and toxic industrial emissions in Portland. The design for this thesis was partially inspired by Downey's and subsequently allows comparison of the results and consideration of the methodological implications of any disparities in findings. Both studies use 2000 census data, employ census tracts as the unit of analysis, and use percent African American, percent African American squared, and percent Hispanic for racial variables. However, both studies rely on different indicators of hazards. Furthermore, Downey uses no control or income variables in his tobit regressions. Also, Downey uses separate models for the two independent variables, so the effects of each independent variable are independent of each other. Finally, Downey does not explain his boundaries used to define the Portland metro area. His sample has 421 tracts, while the analyses presented here have 311 tracts. This difference between samples further stresses the problems associated with methodological inconsistencies.

Model 2 from the regression table offers an alternative design to Downey's (2006) tobit regression of percent black $(\mathrm{p}<.05, \mathrm{~b}=214.27)$, percent black squared $(\mathrm{p}<.05, \mathrm{~b}=-$ 4.54), and percent Hispanic ( $\mathrm{p}<.05, \mathrm{~b}=68.09)$ on average industrial emissions (two entirely different regressions- one for each racial category) at the tract level using 2000 census data. Thus, Model 2 essentially tests the same relationships, but using a different measure for toxic pollution exposure. Ultimately, the findings between the two studies are varied. Using Superfund site presence as the dependent variable, percent Hispanic is insignificant. However, the comparison between Downey's (2006) findings and those 
presented in this thesis offer an interesting conclusion: while Portland's Hispanic's are disproportionately burdened with air toxins, these emissions are unlikely to originate from Superfund sites. A recent Oregon Department of Environmental Quality (2011) study lends support to this hypothesis, which found that residential wood combustion emissions were the most prominent air toxin afflicting Portland's Hispanic population. And while the relationship with percent African American confirms Downey's findings (significant and curvilinear), the Superfund inflection point of 10.8 is much lower than when average emissions are employed as the dependent variable (inflection point=23.61).

Instead of disputing his results, the differences in findings are presumably attributable to methodological differences and confirm how problematic methodological inconsistency is within the environmental inequality literature base as it prevents true comparisons. Unfortunately, the results are unable to assess which method - average toxic emissions or Superfund site presence - are superior. Perhaps this is an area that needs further attention; specifically, a valid and reliable measure needs to be constructed which measures not only toxin proximity, but exposure and magnitude. For a more comprehensive examination of environmental inequality trends, researchers must find a way to effectively evaluate exposure. As lofty of a goal as that may be, it may prove to be the only reliable way to produce truly comparative results.

While the quantitative findings are able to account for the presence of spatial environmental inequality, they are limited in their explanatory power. Specifically, little is known about the processes which create and maintain these spatial-social inequities (Pellow 2000). The qualitative work presented in this thesis is able to contribute to this 
much needed discussion. The formation of environmental inequality in Portland reveals to be a multifaceted and complex process. The qualitative findings clearly point to sociohistorical developments that are unique to Portland. Internal dynamics in Portland are linked to the racially and socioeconomically unequal distribution of communities near Superfund sites and other environmental hazards. While certain features of Portland's past (segregation, redlining, and more) set the stage for status quo economic, housing, and environmental inequalities, a multitude of contemporary forces and actors continue to maintain them.

Portland's history of inequitable development proves to be a primary mechanism that facilitates environmental inequalities. Inequitable development constitutes a unifying theme across all three environmental justice struggles (selective sustainability, the Brownfield showcase, and cumulative exposures) presented in the qualitative findings. Despite various programs that were collaboratively framed to help the environment, various business and governmental organizations, and communities alike, certain segments of Portland routinely receive the short end of the stick and are rarely benefited by Portland's greening and development efforts. Instead, privileged communities reap these benefits while traditionally marginalized communities continue to share the bulk of Portland's environmental hazards. Monetary resources are a driving force in both inequitable development and other specific environmental inequalities. As businesses and governments pursue monetary resources through one avenue or another, environmental justice struggles often emerge. While these powerful stakeholders seek to increase their revenue streams (which is often at the detriment of poor and minority communities), 
marginalized groups are simultaneously fighting for basic needs; particularly environmental safety and economic opportunity.

These findings are consistent with Pellow's (2000) EIF theory that contends that environmental inequalities are a result of the competition for society's valued resources between various stakeholders and when the benefits and burdens of these resources are distributed unevenly. And as demonstrated by sustainability practitioners, Williams and Dame Development, and Portland's business organizations, the ability to effectively marshal resources is critical to "winning" this toxic game. Considering environmental justice research has garnered little theoretical attention (Pellow 2000), this research is able to advance theory-driven conversations around environmental inequality processes. By examining the historical forces that have contributed to the formation of environmental inequalities, this research is able to embed the findings into a much needed theoretical and sociological context.

This research has a few limitations that warrant attention. The quantitative results may be limited by issues of spatial autocorrelation, or the statistical phenomenon where tracts near each other are often more alike than more distant tracts. Smith (2009) used a geographically-based software package (GeoDa) and found spatial autocorrelation to be an issue for his 1990 analysis of Portland Superfund sites. Since many of Portland's Superfund sites are clustered along the Willamette River (and are accordingly often found in tracts adjacent to each other), the logit models may also suffer from spatial autocorrelation and the results should be interpreted with caution. Furthermore, the quantitative analyses are limited by a relatively small amount of events (18 events in 311 
cases), which may hinder proper statistical evaluation. Also, the qualitative sample was relatively low, with only 4 participants interviewed. There are countless other environmental justice advocates in the Portland area who have done significant work on the issue and could bring additional insight on the structural and local forces which have shaped regional environmental inequalities. Thus, the qualitative work is limited by a small sample size that in turn limits the comprehensiveness of the qualitative analyses.

While this thesis research brings new insights to the environmental inequality literature, there are still other areas that are understudied and deserve attention in future research endeavors. Future studies with quantitative designs should examine environmental inequality trends using the most up-to-date data available, namely 2010 census data. As seen in the comparison between Smith's (2009) study and this thesis, continued quantitative analysis of contemporary data sets is crucial to the ability to examine changes and fluctuations in environmental inequality in a given region. Furthermore, plenty of cities have yet to be included in quantitative examinations of environmental inequality and accordingly should be analyzed using 2010 census data. Future qualitative (and mixed methods) research should gather data directly from members of environmental justice communities. While "expert" knowledge is helpful, more research needs to incorporate "ground level" local knowledge from citizens who have lived experiences with environmental inequalities in their homes and workplaces. This will enable a deeper understanding of specific environmental justice struggles and gives groups characterized by powerlessness a much-needed forum for their voices to be heard. 


\section{Contributions and Conclusion}

This thesis brings new insights to the collective understanding of environmental inequality. The research presented in this thesis suggests that environmental inequalities are prevalent in Portland, Oregon. First, the quantitative findings of this research suggest that spatial environmental inequality is present in Portland, with percent African American being the strongest predictor of Superfund site presence. However, the quantitative work ultimately suggests that minimally populated, highly impoverished tracts with a racial makeup of approximately $11 \%$ African American are most likely to house a Superfund site. Secondly, a variety of structural and local forces have played prominent roles in Portland's history of environmental inequalities. The qualitative analyses demonstrate that this is a highly complex process with countless associated stakeholders. Segregated and unsafe housing is one of the most prominent outcomes of this process. However, segregated and unsafe communities prove to be a symptom of larger issue: inequitable development. Manifested through a gamut of historical forces (for example: redlining, urban renewal programs, reverse white flight, predatory housing markets, and selective sustainability) and reinforced by institutional forms of racism (race-class connections, generational wealth disparities, and more), inequitable development represents a unifying force in the creation and maintenance of Portland's environmental inequalities. By examining the histories behind environmental inequalities, this research is able to further understanding of the relationships between communities, the built environment, and social inequality. 


\section{References}

Abbott, Carl. 2001. Greater Portland: Urban Life and Landscape in the Pacific Northwest. Philadelphia, PA: University of Pennsylvania Press.

Asch, Peter, and Joseph J. Seneca. 1978. "Some Evidence on the Distribution of Air Quality." Land Economics 54(August):278-297.

Atlas, Mark. 2002. "Few and Far Between? An Environmental Equity Analysis of the Geographic Distribution of Hazardous Waste Generation.” Social Science Quarterly 83:365-378.

Avery, Robert and Michael Rendall. 2002. "Lifetime Inheritances of Three Generations of Whites and Blacks.” American Journal of Sociology 107(5):1300-1346.

Baden, Brett M. and Don L. Coursey. 2002. "The Locality of Waste Sites Within the City of Chicago: A Demographic, Social, and Economic Analysis." Resource and Energy Economics 24:53-93.

Baden, Brett M., Douglas S. Noonan and Rama Mohana Turaga. 2007. "Scales of Justice: Is There a Geographic Bias in Environmental Equity Analysis?"Journal of Environmental Planning and Management 50(2):163-185.

Baker, Herman. 2007. "Nutrition in the Elderly: Nutritional Aspects of Chronic Disease."Geriatrics 62:21-25.

Blühdorn, Ingolfur. 2000. Post-Ecologist Politics: Social Theory and the Abdication of the Ecologist Paradigm. London: Routledge.

Boone, Christopher G. and Ali Modarres. 1999. "Creating a Toxic Neighborhood in Los Angeles County: A Historical Examination of Environmental Inequity." Urban Affairs Review 35(2):163-187.

Bowen, William M. 2002. "An Analytical Review of Environmental Justice Research: What Do We Really Know?” Environmental Management 29:3-15.

Bowen, William M., Mark J. Salling, Kingsley E. Haynes, and Ellen J. Cyran. 1995. “'Toward Environmental Justice: Spatial Equity in Ohio and Cleveland.' Annals of the Association of American Geographers 85:641-663.

Brown, Phil, Desiree Ciambrone and Lori Hunter. 1997. "Does "Green" Mask Grey? Environmental Equity Issues at the Metropolitan Level." International Journal of Contemporary Sociology 34:141-158. 
Brown, Phil and Judith Kelley. 1996. "Physicians' Knowledge of and Actions Concerning Environmental Health Hazards: Analysis Survey of Massachusetts Physicians." Industrial and Environmental Crisis Quarterly 9:512-542.

Bullard, Robert D. 1983. "Solid Waste Sites and the Black Houston Community." Sociological Inquiry 53:273-288.

-------. [1990] 2000.Dumping in Dixie: Race, Class, and Environmental Quality. Boulder, CO: Westview Press.

-------. 2002. "Confronting Environmental Racism in the Twenty-First Century." Global Dialogue 4(1):34-48.

2005. The Quest for Environmental Justice: Human Rights and the Politics of Pollution. San Francisco, CA: Sierra Club Books.

Bullard, Robert D., Paul Mohai, Robin Saha and Beverly Wright. 2007. Toxic Wastes and Race at Twenty 1987-2007: Grassroots Struggles to Dismantle Environmental Racism in the United States. Cleveland, OH: United Church of Christ Justice and Witness Ministry.

-----. 2008. “Toxic Wastes and Race at Twenty: Why Race Still Matters After All These Years." Environmental Law 38:371-411.

Burch, William R., Jr. 1971. Daydreams and Nightmares: A Sociological Essay on the American Environment. New York: Harper \& Row.

Buttel, Frederick H. and Craig R. Humphrey. 2002. "Sociological Theory and the Natural Environment." Pp. 33-69 in Handbook of Environmental Sociology, edited by R. E. Dunlap and W. Michelson. Westport, CT: Greenwood Press.

Byrne, John, Leigh Glover and Cecilia Martinez, eds. 2002. Environmental Justice: Discourses in International Political Economy. Vol. 8, Energy and Environmental Policy. New Brunswick, NJ: Transaction Publishers.

Čapek, Stella M. 1993. "The "Environmental Justice" Frame: A Conceptual Discussion and an Application." Social Problems 40(1):5-24.

Catton, William R., Jr. and Riley E. Dunlap. 1978. "Environmental Sociology: A New Paradigm." The American Sociologist 13(1):41-49.

Centers for Disease Control, National Centers for Chronic Disease Prevention and Health Promotion. 2003. "Physical Activity and Good Nutrition: Essential Elements to Prevent Chronic Diseases and Obesity."Nutrition in Clinical Care 6:135-138. 
Chakraborty, J. and M. Armstrong. 1997. "Exploring the Use of Buffer Analysis for the Identification of Impacted Areas in Environmental Equity Assessment."Cartography and Geographic Information Systems 24:145-157.

Clark, Richard D., Steven P. Lab, and Lara Stoddard. 1995. “Environmental Equity: A Critique of the Literature.” Social Pathology 1:253-269.

Coalition for a Livable Future. 2007. Regional Equity Atlas. Portland, OR: The Coalition for a Livable Future and Portland State University.

Cohen, Nevin. 1997. "The Politics of Environmental Risk: Perceptions of Risk Assessment in the State Legislatures."Policy Studies Journal 25(3):470-484.

Collin, Robert W. 2008. "Environmental Justice in Oregon: It's the Law." Environmental Law 38:413-455.

Collins, Chiiquita A. 1999. "Racism and Health: Segregation and Causes of Death Amenable to Medical Intervention in Major U.S. Cities." Annals of the New York Academy of Sciences 896:396-398.

Cooper, R.S., J.F. Kennelly, R. Durazo-Arvizu, H. J. Oh, G. Kaplan, and J. Lynch. 2001. "Relationship Between Premature Mortality and Socioeconomic Factors in Black and White Populations of US Metropolitan Areas." Public Health Reports 116(5):464473.

Corburn, Jason. 2002. "Combining Community-Based Research and Local Knowledge to Confront Asthma and Subsistence Fishing Hazards in Greenpoint/Williamsburg, Brooklyn, New York." Environmental Health Perspectives 110:241-8.

Crowder, Kyle and Liam Downey. 2010. "Interneighborhood Migration, Race, and Environmental Hazards: Modeling Microlevel Processes of Environmental Inequality." American Journal of Sociology 115(4):1110-1149.

Curtis, Karen A. and Stephanie McClellan. 1995. "Falling Through the Safety Net: Poverty, Food Assistance and Shopping Constraints in an American City." Urban Anthropology 24:93-135.

DePalma, Anthony. 2004. "Love Canal Declared Clean, Ending Toxic Horror." The New York Times, March 18, A1.

Derezinski, Daniel D., Michael G. Lacy, and Paul B. Stretesky. 2003. "Chemical Accidents in the United States, 1990-1996.”' Social Science Quarterly 84:122-143.

Dillard, Jesse, Veronica Dujon, and Mary King. 2008. Understanding the Social Dimension of Sustainability. New York: Routledge. 
Downey, Liam. 2003. "'Spatial Measurement, Geography, and Urban Racial Inequality.' Social Forces 81:937-954.

-------. 2006. "Environmental Inequality in Metropolitan America in 2000." Sociological Spectrum 26:21-41.

Downey, Liam, Summer Dubois, Brian Hawkins and Michelle Walker. 2008. "Environmental Inequality in Metropolitan America." Organization \& Environment 21(3):270-294.

Downey, Liam and Brian Hawkins. 2008. "Race, Income, and Environmental Inequality in the United States." Sociological Perspectives 51(4):759-781.

Dunlap, Riley E., William Michelson and Glenn Stalker. 2002. "Environmental Sociology: An Introduction." Pp. 1-32 in Handbook of Environmental Sociology, edited by R. E. Dunlap and W. Michelson. Westport, CT: Greenwood Press.

Elkind, Sarah S. 2006. "Environmental Inequality and the Urbanization of West Coast Watersheds." Pacific Historical Review 75(1):53-61.

Gibson, Karen J. "Bleeding Albina: A History of Community Disinvestment, 19402000." Transforming Anthropology 15:3-25.

Grady, Sue C. and Sara McLafferty. 2007. "Segregation, Nativity, and Health: Reproductive Health Inequalities for Immigrant and Native-Born Black Women in New York City."Urban Geography 28(4):377-397.

Hamilton, J. T. 1995. “Testing for Environmental Racism: Prejudice, Profits, Political Power?" Journal of Policy Analysis and Management 14:107-132.

Harper, Charles. 2004. Environment and Society: Human Perspectives on Environmental Issues. $3^{\text {rd }}$ ed. Upper Saddle River, New Jersey: Prentice Hall.

Hird, John A. and Michael Reese. 1998. "The Distribution of Environmental Quality: An Empirical Analysis.” Social Science Quarterly 79(4):693-716.

Holifield, Ryan. 2001. "Defining Environmental Justice and Environmental Racism." Urban Geography 22:78-90.

Hurley, Andrew. 1997, "Fiasco at Wagner Electric: Environmental Justice and Urban Geographyin St. Louis."Environmental History 2:460-481.

Jacobson, Louis. 2009. "Lawmakers Offer Bills to Revive Tax that Benefits Superfund." PolitiFact.com, December 11. Retrieved October 30, 2011 (http://www.politifact.com /truth-o-meter/promises/obameter/promise/318/restore-superfund-program-so-thatpolluters-pay-fo/). 
Johnson, R. Burke. 1997. "Examining the Validity Structure of Qualitative Research." Education 118(2):282-292.

Karouna-Renier, Natalie K., K. Ranga Rao, John J. Lanza, Deeya A. Davis and Patricia A. Wilson. 2007. "Serum Profiles of PCDDs and PCDFs, in Individuals near the Escambia Wood Treating Company Superfund Site in Pensacola, FL." Chemosphere 69(8):1312-1319.

Katznelson, Ira. 2005. When Affirmative Action was White: An Untold History of Racial Inequality in Twentieth-Century America. New York: Norton.

Klausner, Samuel Z. 1971. On Man in His Environment. San Francisco, CA: Jossey-Bass.

Kramer, Michael R. and Carol R. Hogue. 2009. "Is Segregation Bad for Your Health?" Epidemiologic Reviews 31:178-194.

Krieg, Eric J. 1995. “A Socio-Historical Interpretation of Toxic Waste Sites: The Case of Greater Boston." Journal of Economics and Sociology 54:1-14.

Lambert, Timothy W., Lindsay Guyn and Stephanie E. Lane. 2006. "Development of Local Knowledge of Environmental Contamination in Sydney, Nova Scotia: Environmental Health Practice from an Environmental Justice Perspective." Science of the Total Environment 368:471-484.

Lansing, Jewel. [2003] 2005. Portland: People, Politics, and Power, 1851-2001. Corvallis, OR: Oregon State University Press.

Lavalle, Marianne and Marcia Coyle. 1992. "Unequal Protection: The Racial Divide in Environmental Law." The National Law Journal September 21:S2-S12.

LaVeist, Thomas A. and John M. Wallace Jr. 2002. "Health Risk and Inequitable Distribution of Liquor Stores in African American Neighborhoods." Pp. 487-493 in Race, Ethnicity, and Health: A Public Health Reader, edited by T. LaVeist. San Francisco, CA: Jossey-Bass.

Lee, Denny. 2003. "Residents Say Return of Trash Station Reeks of Racism." The New York Times, March 9, Section 14, p. 8.

Lerner, Steve. 2010. Sacrifice Zones: The Front Lines of Toxic Chemical Exposure in the United States. Cambridge, MA: MIT Press.

Maben, Manly. 1987. Vanport. Portland, OR: Oregon Historical Society Press.

Marmot, Michael, Johannes Siegrist and Tores Theorell. 2006. "Health and the Psychosocial Environment at Work." Pp. 97-130 in Social Determinants of Health, $2^{\text {nd }}$ ed., edited by M. Marmot and R. Wilkinson. New York: Oxford University Press. 
Massey, Douglas S. and Nancy A. Denton. 1993. American Apartheid: Segregation and the Making of the Underclass. Cambridge, MA: Harvard University Press.

Massey, Douglas S., Thurston Domina and Jonathan Rothwell. 2009. "Changing Bases of Segregation in the United States." Annals of the American Academy of Political and Social Science 626:74-90.

Massey, Douglas S. and Zoltan Hajnal. 1995. "The Changing Geographic Structure of Black-White Segregation in the United States."Social Science Quarterly 76:527-42.

Mohai, Paul. 1995. "The Demographics of Dumping Revisited: Examining the Impact of Alternate Methodologies on Environmental Justice Research.' Virginia Environmental Law Journal 13:615-653.

Mohai, Paul, and Bunyan Bryant. 1992. Race and the Incidence of Environmental Hazards: A Time for Discourse. Boulder, CO: Westview Press.

Morland, Kimberly, Steve Wing, Ana Diez Roux and Charles Poole. 2002. "Neighborhood Characteristics Associated with the Location of Food Stores and Food Service Places." Pp. 448-462 in Race, Ethnicity, and Health: A Public Health Reader, edited by T. LaVeist. San Francisco, CA: Jossey-Bass.

Napton, Mary Luanne and Frederick. A. Day. 1992. "Polluted Neighborhoods in Texas: Who Lives There?" Environment and Behavior 24(4):508-526.

Noonan, Douglas S. 2008. "Evidence of Environmental Justice: A Critical Perspective on the Practice of EJ Research and Lessons for Policy Design." Social Science Quarterly 89(5):1153-1174.

O'Neil, Sandra George. 2007. "Superfund: Evaluating the Impact of Executive Order 12898." Environmental Health Perspectives 115(7):1087-1093.

Oregon Department of Environmental Quality. 2011. "Environmental Justice Consideration." Oregon Department of Environmental Quality: Portland Air Toxics Solutions Study. Retrieved November 15, 2011 (http://www.deq.state.or.us/aq/toxics /docs/pats/7_25_11 presentation.pdf).

Pastor, Manuel. Jr., Jim Sadd and John Hipp. 2001. "Which Came First? Toxic Facilities, Minority Move-In, and Environmental Justice." Journal of Urban Affairs 23(1):1-21.

Pastor, Manuel. Jr., James L. Sadd and Rachel Morello-Frosch. 2002. "Who’s Minding the Kids? Pollution, Public Schools, and Environmental Justice in Los Angeles." Social Science Quarterly 83:263-280.

Pellow, David. 1999. "Framing Emerging Environmental Movement Tactics: Mobilizing Consensus, Demobilizing Conflict." Sociological Forum 14(4):659-683. 
-------. 2000. "Environmental Inequality Formation: Toward a Theory of Environmental Injustice." American Behavioral Scientist 43:581-601.

-------. 2002. Garbage Wars: The Struggle for Environmental Justice in Chicago. Cambridge, Massachusetts: MIT Press.

-. 2004. "The Politics of Illegal Dumping: An Environmental Justice Framework." Qualitative Sociology 27(4):511-525.

-------. 2007. Resisting Global Toxics: Transnational Movements for Environmental Justice. Cambridge, Massachusetts: MIT Press.

Petrie, Michelle. 2006. "Environmental Justice in the South: An Analysis of the Determinants and Consequences of Community Involvement in Superfund." Sociological Spectrum 26(5):471-489.

Pulido, Laura. 1996. "A Critical Review of the Methodology of Environmental Racism Research.” Antipode 28(2):142-159.

Pulido, Laura, Steve Sidawi and Robert O. Vos. 1996. "An Archaeology of Environmental Racism in Los Angeles." Urban Geography 17(5):419-439.

Ringquist, Evan J. 1997. "Equity and the Distribution of Environmental Risk: The Case of TRI Facilities." Social Science Quarterly 78:811-829.

Rothwell, Jonathon T. and Douglas S. Massey. 2010. "Density Zoning and Class Segregation in U.S. Metropolitan Areas." Social Science Quarterly 91(5):1123-1143.

Saenz, Rogelio. 2005. "Latinos and the Changing Face of America." In The American People: Census 2000, edited by R. Farley and J.Haaga. New York: Russell Sage Foundation.

Saha, Robin and Paul Mohai. 2005. "Historical Context and Hazardous Waste Facility Siting: Understanding Temporal Patterns in Michigan." Social Problems 52(4):618648.

Schnaiberg, Allan. 1980. The Environment: From Surplus to Scarcity. New York: Oxford University Press.

Sicotte, Diane. 2010. "Some More Polluted Than Others: Unequal Cumulative Industrial Hazard Burdens in the Philadelphia MSA, USA." Local Environment 15(8):761-774.

Shandas, Vivek and W. Barry Messer. 2008. "Fostering Green Communities Through Civic Engagement: Community-Based Environmental Stewardship in the Portland Area." Journal of the American Planning Association 74(4):408-418. 
Shaw, Samuel and Daniel Monroe Sullivan. 2011. "'White Night': Gentrification, Racial Exclusion, and Perceptions and Participation in the Arts." City \& Community 10:241264.

Shriver, Thomas E. and Gary R. Webb. 2009. "Rethinking the Scope of Environmental Injustice: Perceptions of Health Hazards in a Rural Native American Community Exposed to Carbon Black." Rural Sociology 74(2):270-292.

Small, Mario Luis and Katherine Newman. 2001. "Urban Poverty after the Truly Disadvantaged: The Rediscovery of the Family, the Neighborhood, and Culture.' Annual Review of Sociology 27:23-45.

Smith, Chad L. 2009. "Economic Deprivation and Racial Segregation: Comparing Superfund Sites in Portland, Oregon and Detroit, Michigan." Social Science Research 38:681-692.

Stafford, Mai and Mark McCarthy. 2006. "Neighborhoods, Housing, and Health." Pp. 297-317 in Social Determinants of Health, $2^{\text {nd }}$ ed., edited by M. Marmot and R. Wilkinson. New York: Oxford University Press.

Sterling, David A., R. Gregory Evans, Brooke N. Shadel, Fernando Serrano, Brenda Arndt, John J. Chen and Lori Harris. 2004. "Effectiveness of Cleaning and Health Education in Reducing Childhood Lead Poisoning Among Children Residing Near Superfund Sites in Missouri." Archives of Environmental Health 59(3):121-131.

Stretesky, Paul and Michael J. Hogan. 1998. "Environmental Justice: An Analysis of Superfund Sites in Florida." Social Problems 45(2):268-287.

Sullivan, Daniel Monroe and Samuel C. Shaw. 2011. "Racial Gentrification and Race: The Case of Alberta Street in Portland, Oregon." Urban Affairs Review 47(3):413432.

Szasz, Andrew. 1994. EcoPopulism: Toxic Waste and the Movement for Environmental Justice. Minneapolis, MN: University of Minnesota Press.

Szasz, Andrew and Michael Meuser. 2000. "Unintended, Inexorable : The Production of Environmental Inequalities in Santa Clara County, California." American Behavioral Scientist 43(4):602-632.

Taylor, David G. 2011. "No Sign of Action from Congress." PolitiFact.com, July 1. Retrieved October 30, 2011 (http://www.politifact.com/truth-o-meter/promises/ obameter/promise/318/restore-superfund-program-so-that-polluters-pay-fo/).

Thomas, David R. 2006. “A General Inductive Approach for Analyzing Qualitative Evaluation Data." American Journal of Evaluation 27:237-246. 
United Church of Christ, Commission for Racial Justice. 1987. Toxic Wastes and Race in the United States: A National Report on the Racial and Socioeconomic Characteristics of Communities with Hazardous Waste Sites. New York: United Church of Christ.

U.S. Census Bureau. 2001. Census 2000. Accessed via FactFinder (2) on April 7, 2011 (http://factfinder2.census.gov/).

U.S. Environmental Protection Agency. 2010a. "About Superfund." U.S. Environmental Protection Agency. Retrieved November 7, 2010 (http://www.epa.gov/superfund/ about.htm/).

- 2010b. "Superfund Site Information System"U.S. Environmental Protection Agency. Retrieved December 3, 2010 (http://cfpub.epa.gov/supercpad/cursites /srchsites.cfm).

-------. 2010c. "EPA Supports Superfund "Polluter Pays" Provision / Agency Submits Administration's Guidance to Congress." U.S. Environmental Protection Agency, June 21. Retrieved October 30, 2011 (http://yosemite.epa.gov/opa/admpress.nsf/ d0cf6618525a9efb85257359003fb69d/6e61eb7ab20b163c8525774900592657).

-------. 2011a. "Introduction to the Hazard Ranking System (HRS)." U.S. Environmental Protection Agency. Retrieved November 1, 2011 (http://www.epa.gov/superfund/ programs/npl_hrs/hrsint.htm).

2011b. "NPL Site Totals by Status and Milestone." U.S. Environmental Protection Agency. Retrieved November 1, 2011 (http://www.epa.gov/superfund/ sites/query/query htm/npltotal.htm).

------. 2011c. "How Sites are Placed on the NPL." U.S. Environmental Protection Agency. Retrieved November 1, 2011 (http://www.epa.gov/superfund/programs /npl_hrs/nplon.htm).

U.S. General Accounting Office. 1983. "Siting of Hazardous Waste Landfills and Their Correlation with Racial and Economic Status of Surrounding Communities." Washington, DC: GAO/RCED 83-168, June 1.

Urban League of Portland. 2009. State of Black Oregon. Retrieved November 18, 2011 (http://www.ulpdx.org/documents/UrbanLeague-StateofBlackOregon.pdf).

Watson, Tara. 2006. "Inequality, Metropolitan Growth, and Residential Segregation by Income." Pp. 1-52 in Brookings-Wharton Papers on Urban Affairs, edited by G. Burtless and J. Rothenberg Pack. Washington, DC: Brookings Institution Press.

Whelan, Amanda, Neil Wrigley, Daniel Warm and Elizabeth Cannings. 2002. "Life in a 'Food Desert."'Urban Studies 39(11):2083-2100. 
Wilkinson, Richard and Michael Marmot, eds. 2003. Social Determinants of Health: The Solid Facts. $2^{\text {nd }}$ ed. Copenhagen, Denmark: World Health Organization.

Williams, David R. and Chiquita Collins. 2001. "Racial Residential Segregation: A Fundamental Cause of Racial Disparities in Health."Public Health Report 116:404416.

Williamson, Dhelia M., Mary C. White, Charles Poole, David Kleinbaum, Robert Vogt and Kari North. 2006. "Evaluation of Serum Immunoglobulins among Individuals Living Near Six Superfund Sites." Environmental Health Perspectives 114(7):10651071.

Wilson, William Julius. 1987. The Truly Disadvantaged: The Inner City, the Underclass, and Public Policy. Chicago, IL: The University of Chicago Press.

Wrigley, Neil, Daniel Warm, Barrie Margetts and Amanda Whelan.2002. "Assessing the Impact of Improved Retail Access on Diet in a 'Food Desert': A Preliminary Report." Urban Studies 39(11):2061-2082.

Yandle, Tracy and Dudley Burton. 1996. "Reexamining Environmental Justice: A Statistical Analysis of Historical Hazardous Waste Landfill Siting Patterns in Metropolitan Texas."Social Science Quarterly 77(3):477-492.

Zuesse, Eric. 1981. "Love Canal: The Truth Seeps Out." Reason, February. Retrieved October 31, 2011 (http://reason.com/archives/1981/02/01/love-canal). 


\section{Appendix: Interview Guide}

[start with a 3-5 minute overview of the project, including qualitative research question (What structural and local forces contribute to environmental inequality in Portland?), "I'm really interested in the history and process of environmental inequality and the multiple stakeholders involved," followed with the consent form]

1. What has been your personal experience (or the experience of your community and communities you've worked with) regarding pollution exposure and environmental justice? Or: What has been your experience with pollutant exposure with the communities you work with? Prompts: What entities (e.g.: government, real estate brokers, businesses, communities, etc) were involved? Who are the key stakeholders in this story? Who or what do you think is most responsible for the toxic exposure? What is the evidence of the exposure? Has anyone paid attention? Was anything done?

2. (if needed) What types of communities were most affected by the toxin exposure? Prompts: Racial minorities? Low income neighborhoods? Immigrants?

3. What do you think explains why these communities were affected? (if not mentioned) Do you think poverty or race were factors? Prompts: Do think one of these was a bigger issue rather than the other? Is one more salient than the other? Neither?

a. What are some of the tangible roots of the problem? (Policy, etc)

b. What are some of the less tangible, more systemic roots of the problem? (inequality

4. Can you share any experiences you've had with Portland metro Superfund sites in particular?

5. What do you think should be done about these sites? How should the problems the communities face be handled?

\section{Potential additional questions:}

- In your experience, how has your environmental justice group responded to environmental inequality?

- How has environmental inequality shaped Portland over the years? 